\title{
Amount and amino acid composition of basal endogenous protein losses at the terminal ileum of broilers
}

\author{
M.C. Blok (Wageningen Livestock Research) \\ A.J.M. Jansman (Wageningen Livestock Research) \\ C.A. Makkink (independent nutritionist)
}

CVB Documentation report nr. 60 December 2017

Wageningen Livestock Research

P.O. Box 338

$6700 \mathrm{AH}$ Wageningen

The Netherlands 


\section{ㄷ Federatie Nederlandse Diervoederketen 2017}

No part of this edition may be copied, photocopied, reproduced, translated or reduced to any electronic medium or machine-readable form, in whole or in part, without specific written permission of the Federatie Nederlandse Diervoederketen (info@diervoederketen.nl).

All copyrights and database rights with respect to this publication are expressly reserved. Nothing in this publication may be reproduced, copied, retrieved, made public or re-used or made available in any way whatsoever to third parties by way of printing, photocopying, microfilm or in any other way unless the Federatie Nederlandse Diervoederketen has given express written permission to do so. This publication has been compiled with great care; however, the Federatie Nederlandse Diervoederketen and Wageningen Livestock Research cannot be held liable in any way for the consequences of using the information in this publication. 


\section{Preface}

Since 1979 a Table based on the apparent fecal digestibility of amino acid in feedstuffs determined with adult roosters has been used for protein and amino acid evaluation of feedstuffs for poultry. Some years ago, when CVB was an activity of the Product Board Animal Feed (PDV), it was recognized that this Table needs updating.

After Ravindran and co-workers made available their database - containing ileal digestibility values of a number of feedstuffs for broilers - to CVB it was decided to replace the existing Table, based on faecal digestibility data, by a new Table, based on ileal digestibility studies.

Further, it was decided to construct a Table based on the standardized ileal amino acid digestibility of feedstuffs in broilers. To do so it was necessary to set values for the basal ileal endogenous losses of individual amino acids to be able to convert experimentally determined apparent ileal digestibility values of feed ingredients into standardized ileal digestibility values.

In the present report the results of a literature review are described evaluating the flow of basal endogenous amino acids at the ileal level in broilers. Based on the data collected, a proposal for the basal endogenous loss of amino acids in broilers has been formulated.

Wageningen, December 2017

M.C. Blok

Former manager of the CVB activity of the Product Board Animal Feed /

Now advisor of the CVB program (executed by Wageningen Livestock Research, department Animal Nutrition on behalf of the Dutch Federation of the Animal Feed Chain) 


\title{
Members of the former CVB Working Group Nutrition and Feed Evaluation Pigs and Poultry (VVVP)
}

\author{
M. C. Blok (secretary) \\ P.J. van der Aar \\ M. van den Brink \\ D. Coremans \\ M. van Erp \\ H. Everts (chair) \\ J. Fledderus \\ W. Gerrits \\ A.J.M. Jansman \\ J.W. Spek
}

\author{
Wageningen Livestock Research, Wageningen \\ Schothorst Feed Research \\ Nederlandse Vereniging Diervoederindustrie (Nevedi) \\ Overleggroep Producenten Natte Veevoeder (OPNV) \\ Nederlandse Vereniging Diervoederindustrie (Nevedi) \\ University Utrecht, Faculty Veterinary Science, \\ Department Nutrition \\ Nederlandse Vereniging Diervoederindustrie (Nevedi) \\ Wageningen University, Animal Nutrition Group \\ Wageningen Livestock Research, Wageningen \\ Wageningen Livestock Research, Wageningen
}

\section{Members of the former Project Group lleal Digestible Amino Acids Poultry (DVAZP)}
M. C. Blok
R.A. Dekker
A.J.M. Jansman
M. van Krimpen
C. Kwakernaak
R. Kwakkel
M. Lensing
B. Swart
C. Makkink
T. Veldkamp
P. Wijtten

\author{
Wageningen Livestock Research, Wageningen \\ Wageningen Livestock Research, Wageningen \\ Wageningen Livestock Research, Wageningen \\ Wageningen Livestock Research, Wageningen \\ Schothorst Feed Research, Lelystad \\ Wageningen University, Animal Nutrition Group, Wageningen \\ Agrifirm, Apeldoorn \\ ForFarmers, Lochem \\ Independent animal nutrition specialist \\ Wageningen Livestock Research, Wageningen \\ Provimi / Cargill, Rotterdam
}

\section{Members of the Technical Committee of the CVB}

B. Boswerger/A. Dijkslag Nederlandse Vereniging Diervoederindustrie (Nevedi)

M. van Erp

J. Fledderus

H. van Laar/C. Geerse

D. van Manen

J. van der Staak

H. Korterink

A. van de Ven

C. van Vuure

G. van Duinkerken

J.W. Spek
Nederlandse Vereniging Diervoederindustrie (Nevedi)

Nederlandse Vereniging Diervoederindustrie (Nevedi)

Nederlandse Vereniging Diervoederindustrie (Nevedi)

Overleggroep Producenten Natte Veevoeders (OPNV)

Land- en Tuinbouworganisatie Nederland (LTO)

Nederlandse Vereniging van Handelaren in Stro, Fourages en

Aanverwante Producten (HISFA)

Nederlandse Vereniging Diervoederindustrie (Nevedi)

$\mathrm{MVO}$, ketenorganisatie voor oliën en vetten

Wageningen Livestock Research, Dept. Animal Nutrition, Wageningen

Wageningen Livestock Research, Dept. Animal Nutrition, Wageningen 


\section{Summary}

In this report literature data on endogenous ileal protein and amino acid losses in broilers are reviewed. The aim was to propose an estimated value for the flow of basal endogenous protein at the terminal ileum and to determine the amino acid composition of the basal endogenous protein. The proposed basal endogenous ileal amino acid flows can subsequently be used to calculate standardized ileal digestible amino acid values for feedstuffs for poultry from experimentally determined apparent ileal digestible amino acids. Basal endogenous ileal amino acids losses are expressed in mg per kg dry matter intake. The quantitative flow of basal endogenous amino acids at the terminal ileum is dependent on the methodology used for quantification, the age of the animals and the presence of phytate and phytase in the diet. From our literature survey we concluded that the nitrogen free feeding method (NFD) and the regression method (REG) are most suitable to determine basal endogenous amino acids at the terminal ileum in broilers. Based on 29 observations from 25 studies with NFD, 6 observations of 4 REG studies, 5 observations of 3 HDP studies and 2 observations from $2 \mathrm{EHC}$ studies, we calculated the basal ileal endogenous amino acid flow in broilers aged 15 to 45 days. The total flow of basal endogenous ileal amino acids amounts $5.90 \mathrm{~g} \mathrm{AA}$ per $\mathrm{kg}$ dry matter intake. The values for basal endogenous ileal flow of the individual amino acids are used by CVB to estimate standardized ileal amino acid digestibility values from apparent amino acid digestibility values of feedstuffs for broilers (see CVB Documentation Report no. 61).

lleal endogenous protein is rich in GLU, ASP, GLY, THR, SER and PRO and rather closely reflects the composition of mucoproteins. 


\section{Contents}

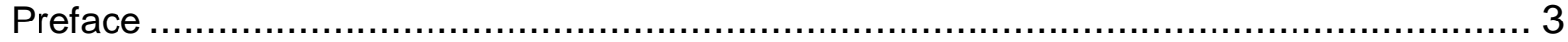

Members of the former CVB Working Group Nutrition and Feed Evaluation

Pigs and Poultry (VVVP)........................................................................ 4

Members of the former Project Group lleal Digestible Amino Acids Poultry (DVAZP) 4

Members of the Technical Committee of the CVB ................................................... 4

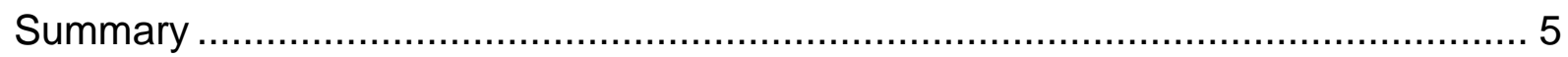

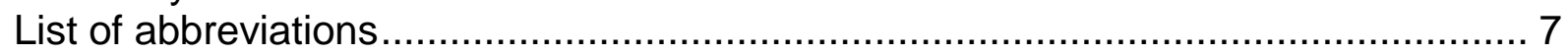

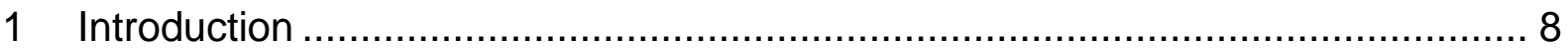

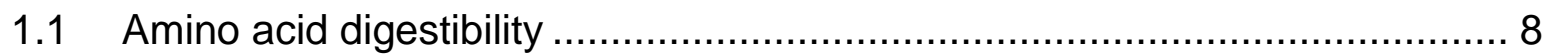

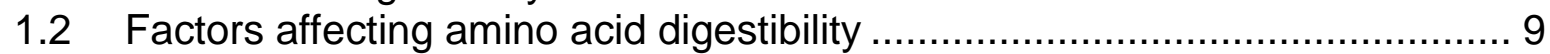

1.3 Endogenous losses ..................................................................... 9

2 Literature on the flow of basal ileal endogenous $\mathrm{N}$ and amino acids in poultry .. 13

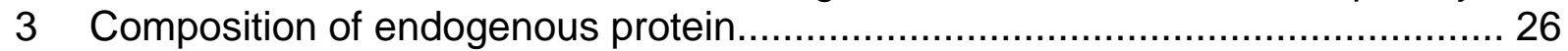

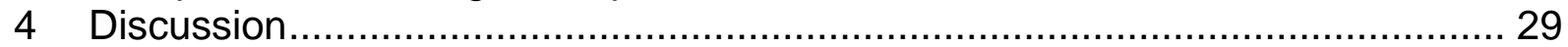

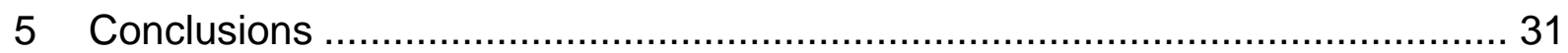

References ................................................................................... 32

Appendix 1. Literature data on endogenous ileal AA flow in broilers.................... 36

1.1 Results for NFD (Nitrogen Free Diets) ................................................. 36

1.2 Results for REG (Regression) method ................................................. 39

1.3 Results for HDP (Highly digestible protein) method................................. 40

1.4 Results for EHC (Enzymatic Hydrolysed Casein) method .......................... 41

Appendix 2. Literature data on the amino acid composition of ileal endogenous protein in poultry. ................................................... 42

Appendix 3. Proposed basal endogenous ileal AA flow (g per kg DMI)................ 44 


\section{List of abbreviations}

AA

ADC

AIDC

ALA

ARG

ASP

CP

CYS

DM

DMI

EHC

GC

GLU

GLY

GuP

HIS

I

IEAAL

ILE

LEU

LYS

MET

$\mathrm{N}$

NFD

PHE

PRO

REG

STDEV

SER

SIDC

THR

TRP

TYR

VAL

Amino acid

Apparent digestibility coefficient (\%)

Apparent ileal digestibility coefficient (\%)

Alanine

Arginine

Asparagine + Aspartic acid (which is analysed as Asparagine)

Crude protein

Cysteine

Dry matter

Dry matter intake

Enzymatically hydrolyzed casein

Guanidinated casein

Glutamine + Glutamic acid (which is analysed as Glutamine)

Glycine

Guanidinated protein

Histidine

Indigestible marker

lleal endogenous AA losses ( $\mathrm{g} / \mathrm{kg} \mathrm{DMI})$

Isoleucine

Leucine

Lysine

Methionine

Nitrogen

Nitrogen free diet

Phenylalanine

Proline

Regression method

Standard deviation

Serine

Standardized ileal digestibility coefficient (\%)

Threonine

Tryptophan

Tyrosine

Valine 


\section{Introduction}

Evaluation of dietary proteins is more precise if expressed in terms of contents of digestible amino acids rather than contents of total amino acids (Dalibard \& Paillard, 1995; Rostagno et al., 1995; Williams, 1995; Parsons, 1996; Honda et al., 2010). Nutrients that are not digested and absorbed in the small intestine may be fermented by bacteria in the caeca and colon. Amino acids produced during protein fermentation in the hindgut are not utilized by the host animal as source of amino acids. Therefore, ileal digestible amino acids provide a better representation of amino acids that become available to the animal than amino acids digested over the total digestive tract. Therefore, the digestibility of protein and amino acids at the ileal level is a valuable characteristic of the nutritional value of feed ingredients.

lleal digesta contains not only undigested dietary material, but also endogenous components, such as digestive enzymes, mucus and desquamated epithelial cells. These endogenous losses can be quantified using different experimental methods.

The objective of this study is to review literature data on endogenous ileal amino acid losses in broilers. The ultimate goal is to propose a reference value for the flow of basal endogenous protein at the terminal ileum and to determine the amino acid composition of the endogenous protein. These basal endogenous ileal amino acid losses will be used by CVB to calculate standardized ileal digestible amino acids for feedstuffs for poultry from experimentally published data on the apparent ileal digestibility of amino acids in order to establish a Table on standardized ileal digestibility values of amino acids in feedstuffs for poultry (see CVB Documentation report no. 61).

\subsection{Amino acid digestibility}

Digestibility is defined as the fraction of a nutrient ingested that is digested and absorbed by the animal, i.e., not flowing to the hindgut (ileal digestibility) or excreted in the faeces (faecal or total tract digestibility). The amino acid digestibility can therefore be calculated as follows:

$\operatorname{ADC}(\%)=\left(\left(A A_{\text {diet }}-A A_{x}\right) / A A_{\text {diet }}\right)^{*} 100$, Where:

$A D C=$ apparent digestibility coefficient (either at ileal or faecal level)

$\mathrm{AA}_{\text {diet }}=$ dietary amino acid input

$A A_{x}=$ amino acid output at terminal ileum or in excreta

The excreta of poultry consist not only of faeces, but also of urine. Urinary nitrogen is therefore a source of error in determining crude protein digestibility in poultry. In the hindgut, ileal undigested proteins can be partly fermented by the gut flora. On the other hand, the gut flora may also synthesize amino acids. However, amino acids from protein digested in the hindgut are not utilized by the host animal. Hence, faecal digestibility of amino acids does not represent the amino acids that actually become available to the animal. Therefore, the digestibility at the end of the ileum is considered a better indication of the availability of protein and amino acids than the faecal digestibility (Ravindran \& Bryden, 1999; Ravindran et al., 1999; Kadim et al., 2002). Ileal digestibility can be determined with the use of birds fitted with an ileal cannula, or by collecting ileal digesta at slaughter (Bryden at al., 2008). Ileal cannulation has been developed for adult cockerels but is less feasible for young, growing broilers. Because quantitative collection of ileal digesta is not possible, inert digestibility markers are used to estimate nutrient digestibility. Such markers should not interfere with digestive processes, should not be absorbed and should behave similar to the nutrient of interest in the GI tract. The amino acid digestibility is then calculated as follows:

$$
\operatorname{AIDC}(\%)=100-\left(\left(I_{\text {diet }} \text { * } A A_{\text {digesta }}\right) /\left(I_{\text {digesta }} \text { * } A A_{\text {diet }}\right) * 100\right) \text {, }
$$

Where: 
AIDC = apparent ileal digestibility coefficient (\%)

$A A_{\text {diet }}=$ concentration of amino acid in diet

$\mathrm{AA}_{\text {digesta }}=$ concentration of amino acid in ileal digesta

$I_{\text {diet }}=$ concentration of marker in diet

$I_{\text {digesta }}=$ concentration of marker in ileal digesta

\subsection{Factors affecting amino acid digestibility}

Amino acid digestibility depends on the feedstuff and the type of protein. Also, other components of the diet (e.g. crude fibre and antinutritional factors) affect the amino acid digestibility. Apart from these dietary factors, animal characteristics - age, physiological status, health status - influence amino acid digestibility. Interactions between feed ingredients and animal category have been found by, e.g., Huang et al. (2006). The nature of the birds (broilers, layers or roosters) influences apparent ileal digestibility values of amino acids in some feed ingredients. In addition, variation in amino acid digestibility values will occur depending on the assay procedure and analytical methods used. The amino acid digestibility of a raw material not only depends on the amino acid digestibility of the test ingredient included in the diet, but also on the characteristics of the other ingredients in the test diet. So the dietary 'matrix' can affect the amount of endogenous protein that passes the terminal ileum. With a high inclusion level of the product to be tested as the only protein source in the diet, the influence of the dietary matrix is likely small. However, for test ingredients with a low inclusion level, a correction on the amino acid digestibility values may be necessary to correct for the influence of other dietary components.

\subsection{Endogenous losses}

The passage of feedstuffs through the digestive tract causes endogenous losses.

Endogenous nitrogen or crude protein $\left(\mathrm{CP}, 6.25^{\star} \mathrm{N}\right)$ and amino acids $(\mathrm{AA})$ are defined as the amount of these constituents in ileal digesta or faeces, which do not originate from the diet (Souffrant, 1991). Endogenous proteins consist of salivary and gastric secretions, pancreatic and bile secretions, small intestinal secretions, mucoproteins and sloughed epithelial cells (Jansman et al., 2002). At the terminal ileum, the digesta also contains some microbial protein, originating from either dietary protein or endogenous proteins as a result of activity of microbiota in the small intestine. This bacterial protein is strictly not endogenous, but is usually included in estimations of endogenous protein (Moughan et al., 2005; Milner-Williams et al., 2009), since it has a non-dietary origin.

In diets with only one protein source, the apparent amino acid digestibility coefficient increases with increasing the inclusion level of amino acid in the diet: at a low intake level, the endogenous amino acid losses represent a relatively large part of the amino acids present in the digesta at the terminal ileum. Therefore, in case of two ingredients with identical true amino acid digestibility and identical inclusion levels in the diet but with a low and high amino acid content, the ingredient with a low amino acid content will have a lower calculated apparent ileal amino acid digestibility than the ingredient with the high amino acid content. To overcome this methodological problem, the basal endogenous protein and amino acid losses at the terminal ileum should be taken into account.

At the terminal ileum, a distinction can be made in basal endogenous losses (losses due to the passage of dry matter) and specific endogenous losses (losses induced by the feedstuff itself, e.g., caused by antinutritional factors and dietary fibre). Basal endogenous losses can be defined as the inevitable losses closely associated with the metabolic functions of the animal and are independent of the diet type (Cowieson et al., 2009). The basal endogenous crude protein or amino acid flow is independent of the composition of the test feedstuff and proportional to the dry matter intake (Jansman et al., 2002; Lemme et al., 2004). 
Figure 1 shows the different fractions that comprise the amino acids recovered in the digesta at the terminal ileum in dependence of the dietary protein and amino acid intake.

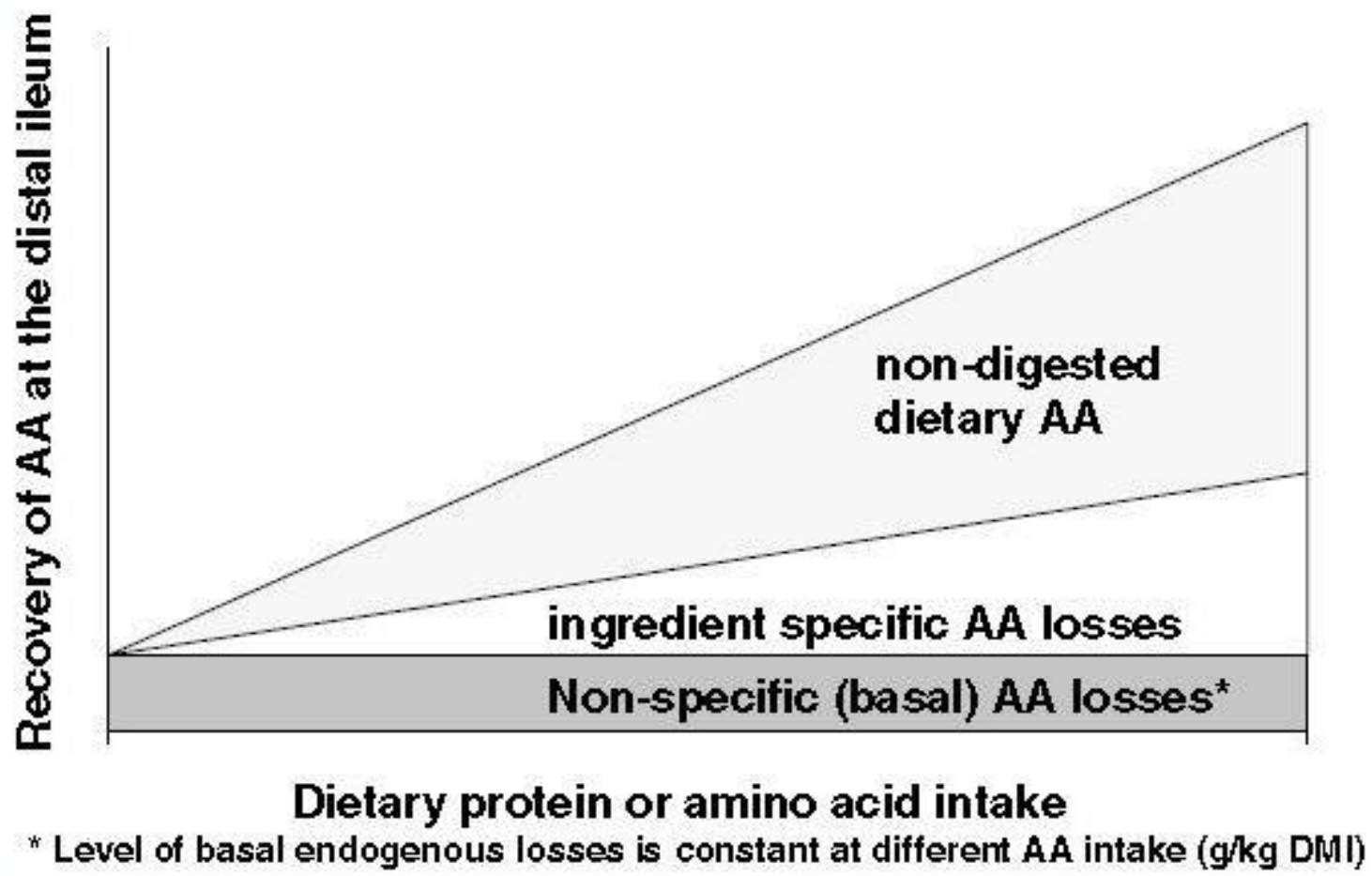

Figure 1. Amino acid losses at the distal ileum as affected by the dietary protein and amino acid intake (Lemme et al., 2004).

The basal endogenous losses may be accounted for in the determination of ileal amino acid digestibility, yielding the standardized ileal amino acid digestibility values. Standardized ileal amino acid digestibility (SID) values provide better estimates of the AA availability in feedstuffs than apparent ileal digestibility values (AID). In the literature it is often stated that SID values are additive for the feedstuffs comprising the diet (Angkanaporn et al., 1996; Stein et al., 2005, Adedokun et al., 2011), whereas for AID values this would not be the case. This statement can be challenged, in case AID values of feed ingredients are properly calculated, taking into account amino acid losses induced by the non-test ingredient part of the experimental diet. The latter implies that AID values of test ingredients are principally different from AID values of the experimental diet containing the test ingredient.

To prevent confusion, and in line with developments on the evaluation of protein and amino acids in feed ingredients for poultry, CVB has decided to construct a new table for the amino acid digestibility of feedstuffs in poultry based on the concept of Standardized lleal Digestibility values.

Standardized amino acid digestibility is calculated as follows (Lemme et al., 2004; Opapeju et al., 2006; Bandegan et al.; 2010):

SIDC $(\%)=A I D C+[($ basal IEAAL, in $\mathrm{g} / \mathrm{kg}$ DM intake $) /($ AA content of the diet, in $\mathrm{g} / \mathrm{kg} \mathrm{DM})]$ *100,

Where:

IEAAL = ileal endogenous AA losses. 
The SIDC values are additive and data are less dependent of the method used to determine AIDC. The contents of standardized ileal digestible AA in feed ingredients can be calculated from the SIDC (\%) values and the gross AA content (g/kg) (Lemme et al., 2004):

Standardized ileal digestible AA content $(\mathrm{g} / \mathrm{kg})=$ gross $A A$ * $(S I D C / 100)$

To determine the quantity of endogenous amino acids at the terminal ileum, various methods can be applied (Table 1).

Methods NFD (Nitrogen Free Diet ) and HDP (Highly Digestible Protein) may be considered representative of basal losses occurring irrespective of feed ingredient or dietary composition. Feed-ingredient specific losses are not measured by these classical methods (Lemme et al., 2004). The methods GuP (Guanidinated Protein) and IDT (Isotope Dilution Technique) yield estimations of total, sum of basal and specific, endogenous losses.

Each method has advantages and disadvantages. In Chapter 2, scientific publications on basal ileal endogenous amino acid flows in broilers are evaluated. The factors influencing results are described and conclusions are drawn as to which method should be preferred to estimate the flow of basal ileal endogenous amino acids in poultry.

In Chapter 3, an overview is given of literature data on the composition of ileal endogenous losses in poultry.

Chapter 4 discusses the literature and in Chapter 5 conclusions are given. 
Table 1. Methods applied to estimate basal ileal endogenous crude protein and/or amino acids losses

\begin{tabular}{|c|c|c|c|c|c|}
\hline Method & Description & Assumption/principle & Advantages & Disadvantages & References \\
\hline NFD & $\mathrm{N}$-free diet & $\begin{array}{l}\text { All CP and AA in ileal digesta are of } \\
\text { endogenous origin and represent the } \\
\text { basal or minimum endogenous flow. }\end{array}$ & Easy to perform. & $\begin{array}{l}\text { The digestive physiology of the bird } \\
\text { changes; protein and amino acids } \\
\text { metabolism is disturbed. }\end{array}$ & $\begin{array}{l}\text { Jansman et al, } 2002 \\
\text { Lemme et al., } 2004 \\
\text { Also see paragraph } \\
2.1 .1 .1\end{array}$ \\
\hline HDP & $\begin{array}{l}\text { Diet containing highly } \\
\text { digestible protein } \\
\text { sources (casein, } \\
\text { wheat gluten) }\end{array}$ & $\begin{array}{l}\text { The true CP and AA digestibility of casein } \\
\text { and wheat gluten is } 99 \% \text {. Casein and } \\
\text { wheat gluten do not induce any specific } \\
\text { secretion of endogenous CP and AA. }\end{array}$ & $\begin{array}{l}\text { No disturbance of } \\
\text { protein metabolism }\end{array}$ & $\begin{array}{l}\text { It appears that the endogenous losses } \\
\text { increase with increasing levels of HDP } \\
\text { in the diet. }\end{array}$ & $\begin{array}{l}\text { Jansman et al, } 2002 \\
\text { Lemme et al., } 2004 \\
\text { Also see paragraph } \\
2.1 .1 .2\end{array}$ \\
\hline REG & $\begin{array}{l}\text { Regression method: } \\
\text { graded CP levels in } \\
\text { the diet }\end{array}$ & $\begin{array}{l}\text { The values obtained by zero-extrapolation } \\
\text { of the CP level in the diet are considered } \\
\text { to reflect an estimate for the ileal flow of } \\
\text { basal endogenous ileal CP and AA. }\end{array}$ & $\begin{array}{l}\text { No disturbance of } \\
\text { protein metabolism }\end{array}$ & $\begin{array}{l}\text { Different levels of protein and therefore } \\
\text { more experimental groups and more } \\
\text { animals are required than with other } \\
\text { methods. Extrapolation will be less } \\
\text { accurate or inaccurate when lowest CP } \\
\text { level is much higher than } 0\end{array}$ & $\begin{array}{l}\text { Jansman et al, } 2002 \\
\text { Lemme et al., } 2004 \\
\text { Also see paragraph } \\
2.1 .1 .2\end{array}$ \\
\hline $\mathrm{EHC}$ & $\begin{array}{l}\text { Enzymatically } \\
\text { hydrolyzed casein } \\
\text { (EHC) - ultrafiltration } \\
\text { - peptides }\end{array}$ & $\begin{array}{l}\text { It is assumed that all endogenous } \\
\text { nitrogen (protein) in the ileal digesta is } \\
\text { found in the ultra-filtrated fraction with a } \\
\text { molecular weight of }>10,000 \mathrm{Da} \text {. This is } \\
\text { considered as the basal ileal endogenous } \\
\mathrm{N} \text { and AA flow. }\end{array}$ & $\begin{array}{l}\text { No disturbance of } \\
\text { protein metabolism }\end{array}$ & $\begin{array}{l}\text { It appears that the endogenous losses } \\
\text { increase with increasing levels of EHC } \\
\text { in the diet. }\end{array}$ & $\begin{array}{l}\text { Jansman et al, } 2002 \\
\text { Lemme et al., } 2004 \\
\text { Also see paragraph } \\
2.1 .1 .2\end{array}$ \\
\hline NFD-pi & $\begin{array}{l}\mathrm{N} \text {-free diet with } \\
\text { parenteral infusion of } \\
\text { amino acids }\end{array}$ & $\begin{array}{l}\text { Similar to method NFD, except for the } \\
\text { application of an intravenous infusion of a } \\
\text { balanced solution of free AAs, in order to } \\
\text { avoid disturbances to protein and AA } \\
\text { metabolism. }\end{array}$ & $\begin{array}{l}\text { Less disturbances to } \\
\text { protein and AA } \\
\text { metabolism than } \\
\text { with NFD method. }\end{array}$ & $\begin{array}{l}\text { More complicated trials and more stress } \\
\text { to animals. No studies with broilers or } \\
\text { other types of chickens }\end{array}$ & Jansman et al, 2002 \\
\hline GuP & $\begin{array}{l}\text { Homoarginine } \\
\text { technique, or } \\
\text { guanidinated protein } \\
\text { method (GuP) }\end{array}$ & $\begin{array}{l}\text { Takes into account both basal and } \\
\text { specific endogenous losses. It is assumed } \\
\text { that guanidinated protein, where part of } \\
\text { the lysine is converted to homoarginine, } \\
\text { behaves in the same way as lysine in the } \\
\text { digestive tract and metabolism. }\end{array}$ & $\begin{array}{l}\text { Animals are in a } \\
\text { physiologically } \\
\text { 'normal' state. } \\
\text { Applicable to all } \\
\text { protein sources. }\end{array}$ & Relatively expensive method. & $\begin{array}{l}\text { Lemme et al., } 2004 \\
\text { Hagemeister \& } \\
\text { Erbersdobler, } 1985 \\
\text { Boisen \& Moughan, } 1996\end{array}$ \\
\hline IDT & $\begin{array}{l}\text { Isotope dilution } \\
\text { technique, }{ }^{15} \mathrm{~N}\end{array}$ & $\begin{array}{l}\text { Takes into account both basal and } \\
\text { specific endogenous losses. } \\
\text { Assumptions are made regarding the } \\
\text { amino acids pool in the body. }\end{array}$ & $\begin{array}{l}\text { Animals are in a } \\
\text { physiologically } \\
\text { 'normal' state. }\end{array}$ & Complicated and expensive method. & Lemme et al., 2004 \\
\hline
\end{tabular}




\section{Literature on the flow of basal ileal endogenous $\mathrm{N}$ and amino acids in poultry}

For pigs (Jansman et al., 2002), the basal endogenous loss of amino acids (expressed as $\mathrm{g}$ AA per $\mathrm{kg} \mathrm{DMI}$ ) is calculated as follows: first the basal endogenous flow of nitrogen ( $\mathrm{g} \mathrm{N}$ per $\mathrm{kg}$ DMI) was estimated and secondly the amino acids composition (g AA per $16 \mathrm{~g}$ of N) of the basal endogenous protein is estimated, both based on data in published studies.

For poultry, this approach was not applicable: many references do not state the basal endogenous $\mathrm{N}$ flow, and do not report data on all amino acids.

Therefore, in the present study, data on basal endogenous losses of amino acids were derived directly from published research of amino acid flows at the terminal ileum. In addition, literature on the amino acid composition of endogenous protein in poultry has been collected in the literature search and are discussed in the present report (see Chapter 3).

The latter data, however, have not been used to estimate losses of basal endogenous amino acids.

\subsection{Basal endogenous amino acids flow}

As stated in Chapter 1, basal endogenous losses are induced by the intake and passage of feed through the gastro-intestinal tract. Therefore, basal endogenous amino acids flows are expressed as mg AA per kg of Dry Matter Intake (DMI).

Several authors have published data for the basal endogenous amino acids flow in broilers. When evaluating such data, several factors should be taken into account: the age of the birds, the experimental method employed (nutritional management, digesta collection method), the diets used (composition, presence of antinutritional factors, level of crude fibre), and other relevant aspects.

\subsubsection{Effect of experimental method on endogenous losses}

The two methods most frequently used for the determination of the basal endogenous AA losses at the terminal ileum are the $\mathrm{N}$-free diet method (NFD) and the regression (REG) method.

\subsubsection{N-free method (NFD)}

The most frequent method used is the NFD. A protein- free diet is fed and all $\mathrm{N}$ and amino acids present in ileal digesta are considered of endogenous origin. The diet is composed to a large proportion of starch and/or sugar (>80\%), small amounts of fibre (e.g. cellulose) and vegetable oil (e.g. soya oil). Further mineral ingredients, a vitamin premix and a trace element premix are added to cover the animal's requirements for these nutrients.

In many studies in which the standardized ileal amino acid digestibility is presented one of the treatments is a NFD to correct to AID values to SID values.

One of the disadvantages of the NFD is that prolonged feeding of the diet may result in disturbances in the protein metabolism. Enhanced levels of proline (PRO) in the ileal digesta is a clear sign of this phenomenon. However, it is sometimes difficult to evaluate the impact of this disturbance. E.g., in a study of Ravindran et al. (2009), in which chickens were fed a NFD from day 32-35 (so for only four days), the ileal PRO flow was $1072 \mathrm{mg} / \mathrm{kg} \mathrm{DMl}$, much higher than in birds fed a diet containing 5, 10, 15 or $20 \%$ EHC (where the loss was 561 , 595,590 and $706 \mathrm{mg} \mathrm{PRO} / \mathrm{kg} \mathrm{DMI}$, respectively) (see also left panel of Figure 1). Contrary, Golian et al. (2008), feeding a NFD and diets with 5, 10 and 15\% of EHC from day 15-21 (so for six days), observed a linear increase in PRO content in the ileal digesta (see also right panel of Figure 2). 


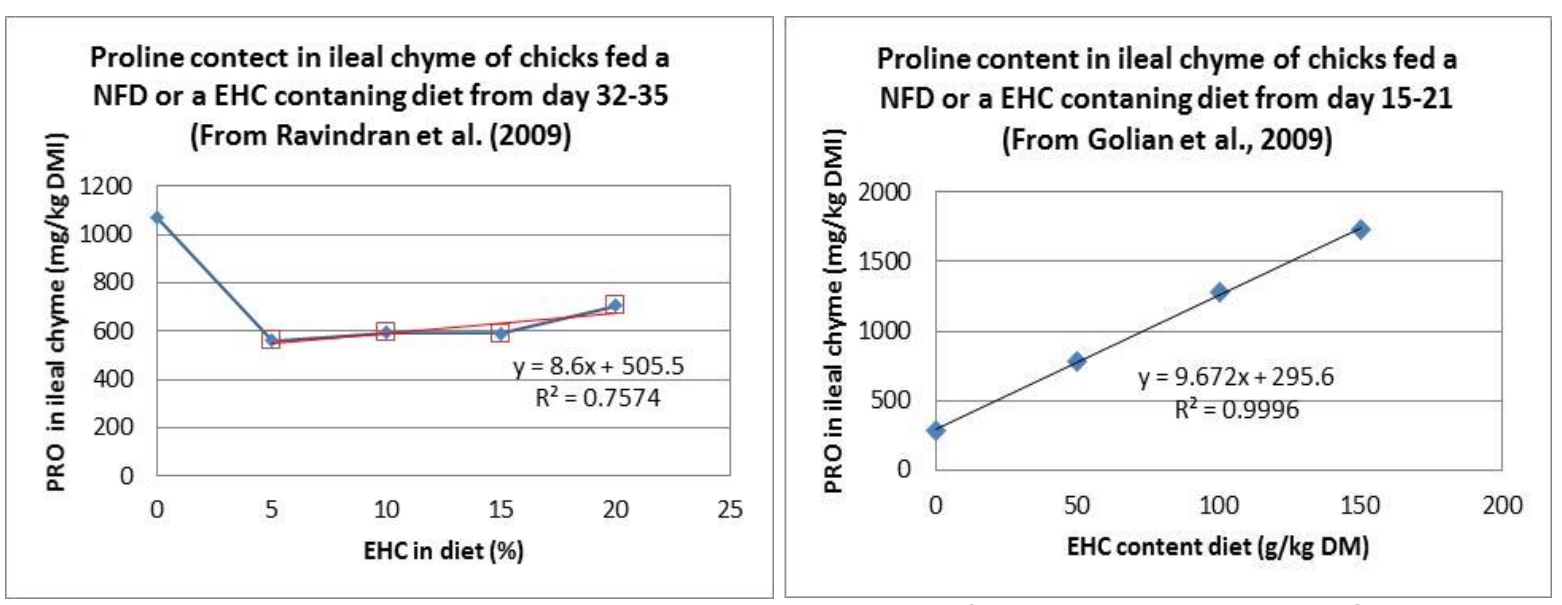

Figure 2. Relationship between the inclusion level of EHC in the diet on the PRO content in ileal digesta as determined by Ravindran et al. (2009) in broilers at 35 days of age (left panel) and by Golian et al. (2008) at 21 days of age. In the left panel the trend line depicted has been calculated for the EHC percentages in the diet from 5 to $20 \%$.

With respect to the composition of the NFD Kong and Adeola (2013) studied whether, at a constant total level of starch plus dextrose, the ratio starch:dextrose would influence the ileal endogenous amino acid flow in broiler chickens at 3 weeks of age. Varying the corn starch:dextrose ratio from 840:0 to 283:566 there were no significant differences, but at a ratio of 0:849 the endogenous $\mathrm{N}$ and amino acid flow was significantly increased, suggesting that the use of diets with a starch:dextrose ratio $>0.5$ should be preferred.

Kluth and Rodehutscord (2009) studied the effect of fibre on the inevitable endogenous amino acid losses by using the REG method. This method uses a series of diets with identical amino acid patterns but with different amino acid levels. Subsequently, the amount of amino acids in the ileal digesta is plotted against the amino acids in the diets. The basal endogenous flow is calculated by extrapolation to zero amino acid level in the diet. Kluth and Rodehutscord (2009) prepared two series of diets with identical amino acid composition but different protein levels, with fibre levels of 30 and $80 \mathrm{~g} / \mathrm{kg}$, respectively. At $80 \mathrm{~g}$ fibre $/ \mathrm{kg}$ the endogenous $\mathrm{N}$ flow was $16.3 \mathrm{~g} / \mathrm{kg} \mathrm{DMI}$, being significantly higher than at $30 \mathrm{~g}$ fibre $/ \mathrm{kg}(11.7$ $\mathrm{g} / \mathrm{kg} \mathrm{DMI})$.

These observations indicate that standardisation of the composition of a NFD for determination of the endogenous amino acid flow is necessary. In practice most NFD used contain large amounts of starch, relative to dextrose, and low fibre levels (mostly 40-50 g/kg cellulose is added). Adedokun et al. (2011) have proposed an ingredient composition for a NFD to be used in poultry studies to determine the amino acid flow at the terminal ileum. In view of the recent observations of Kong and Adeola (2013) the proposed starch:dextrose ratio of 0.31 may be relatively low.

\subsubsection{HDP, EHC and REG method}

In the HDP method, diets containing highly digestible protein sources (e.g. casein, wheat gluten, EHC, guanidated casein) are used. It is assumed that the true digestibility of protein is very high and the indigestible amino acid fraction is negligible, compared to the amount of basal endogenous. Also in the regression (REG) method mostly diets with highly digestible protein sources are used. Therefore, these two methods are discussed simultaneously here. A prerequisite for determination of the basal endogenous losses by using the REG method is that the amino acid composition of the protein fraction in the diets is identical and that only the protein levels differ. This was not the case in the study of Siriwan et al. (1993) who used different protein sources (wheat, sorghum, soybean meal, meat meal and casein) at varying ratios to obtain different levels of CP in the diets. Therefore, this study in fact is not suitable to determine the endogenous amino acid losses. The same was the case in the study of lyayi (2013) who used a basal diet with maize, soybean meal and wheat gluten as protein sources 
and two experimental diets with 15 and $30 \%$ cowpeas (exchanged against maize starch) and determined the intercept $c$ with the regression model $y=a^{*} C P+c$.

Ravindran et al (2004) found that ileal endogenous $\mathrm{N}$ and amino acid flows were higher with the EHC method (20\% EHC in the diet) and GuC method (17.5\% guanidated casein in the diet) than with the NFD method. They concluded that the presence of protein and peptides in the gut increased endogenous flow of $\mathrm{N}$ and amino acids. A similar result was reported in pigs, e.g. by Hodgkinson et al. (2000b) who also used graded levels of enzymatically hydrolysed casein. Nevertheless Ravindran et al. (2004) concluded that 'the use of EHC and $\mathrm{GuC}$ methods enables the measurement of ileal endogenous losses in chickens under normal physiological conditions.' Also in humans it was shown that the presence of protein and peptides in the gut increase the endogenous flow of $\mathrm{N}$ and amino acids (Moughan et al., 2005).

Ravindran et al. (2009) and Golian et al (2008) both used the REG method with EHC as the sole protein source. Ravindran et al. (2009) used EHC diets up to $200 \mathrm{~g} \mathrm{EHC/kg}$ and determined the undigested ileal flow at day 35, after 4 days of feeding the experimental diets. Golian et al. (2008) used diets up to $150 \mathrm{~g} \mathrm{EHC} / \mathrm{kg}$, fed the experimental diets for 5 days and determined the undigested ileal flow at day 21 . In Figure 2 the remarkable difference between these two studies in the PRO content in the ileal digesta after feeding a NFD was already highlighted. In the study of Golian et al. (2008), investigating both EHC and intact casein, highly significant linear relationships were found between amino acid contents in the ileal digesta and the protein content in the diet for all amino acids and for both protein sources. For the EHC diets the relationship showed a quadratic nature for four amino acids (GLU, ILE, SER and VAL), whereas a significant quadratic relationship for only one amino acid (MET) was found with the casein diets. Ravindran et al. (2009), using EHC diets, also found highly significant linear relationships for all amino acids, Further, for 11 of the 17 amino acids analysed (PRO, ALA, ARG, HIS, ILE, LEU, LYS, MET, PHE, TYR and VAL) there was also a significant quadratic relationship.

As the question whether the relationship between the amino acid content in digesta (expressed as $\mathrm{mg} / \mathrm{kg} \mathrm{DMI}$ ) to the protein level of the diet, originating from one single protein source, is linear and/or quadratic of nature is very essential, the results of Golian et al. (2008) and Ravindran et al. (2009) were considered in more detail. By doing this, we recognised a fundamental difference between the quadratic relationships found in these two studies. This is illustrated in Figure 3 for serine (SER).
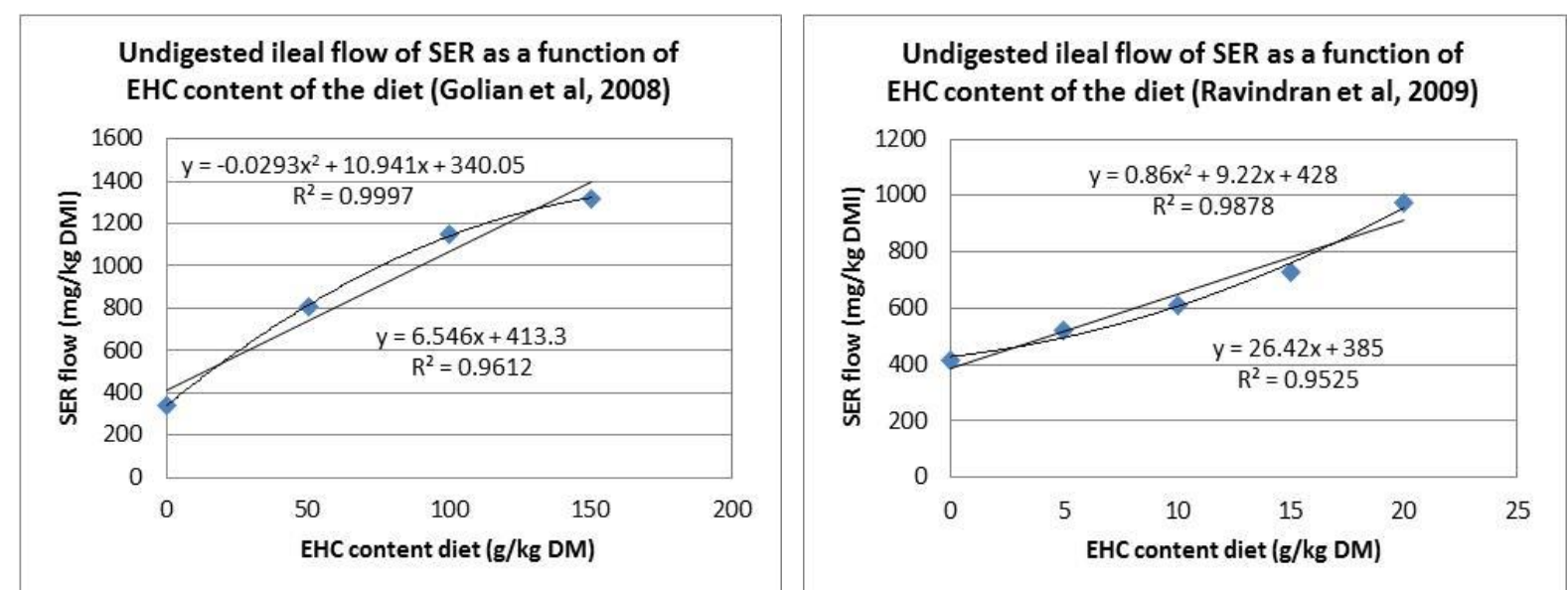

Figure 3. Effects of dietary inclusion level of EHC on the ileal flow of SER as found by Golian et al (2008) (left figure) and Ravindran et al. (2009 (right figure)

In the study of Golian et al. (2008) the fractional gain in the SER flow diminished with increasing EHC content of the diet, whereas in the study of Ravindran et al. (2009) the fractional gain increased. Per study the same pattern was found for all amino acids with a significant quadratic relationship between ileal amino acid flow and protein content of the diet. The difference in response between these two studies suggests different underlying 
mechanisms, which, in this case, is highly unlikely. Therefore, before looking for physiological explanations for quadratic relationships that are statistically significant, the question has to be answered whether such relationships (in addition to being statistically highly significant linear relationships) pertinently should not be ascribed to experimental and analytical inaccuracies. Further, it should be explained why the nature of the relationship is different for individual amino acids. In addition, in the discussion with respect to the origin of the increased amino acid flow with increasing levels of highly digestible protein sources in the diet, the endogenous origin of the increased ileal AA flow is strongly emphasized. Indeed, there are indications in the literature that protein sources used in the HDP and REG method may increase endogenous secretions. In line with Lemme et al, (2004), Ravindran et al. (2009) extensively discussed the various options that proteins or peptides in the gut themselves give rise to specific endogenous losses of varying amounts, e.g., increased secretion of digestive enzymes, increased secretion of (eventually subsequently partially hydrolysed) mucin or specific secretions caused by bioactive peptides They refer to a study by Claustre at al. (2002) who found stimulating effects of enzymatic hydrolysates of casein on mucin secretion in rats. This seems to be a specific casein effect, since guanidinated soybean meal does not affect ileal endogenous flow in pigs (Zhang et al., 2005). From a study with rats (Deglaire et al., 2007) it also appeared that peptides derived from casein increase endogenous protein losses. However, in a later study, Deglaire et al. (2008) compared the effect of intact casein and a hydrolysate from the same batch of casein. In this study no stimulatory effect of casein peptides on the ileal endogenous protein loss was found. It would be worthwhile to demonstrate whether and to which extent the increased amino acid flow at the terminal ileum is of endogenous origin e.g. by using a highly digestible uniformly ${ }^{15} \mathrm{~N}$ labelled protein source. For the time being it is assumed that the increase in amino acid content in digesta at the terminal ileal with increasing protein content of the diet should be ascribed to an incomplete ileal digestibility of the highly digestible protein source. For the study of Golian et al. (2008) a mean amino acid standardized ileal digestibility was calculated of 95 end $93 \%$ for casein and EHC, respectively.

In a number of studies the endogenous losses are determined with the REG method, using casein as protein source (Adedokun et al., 2007a; Adedokun et al. 2007c; Adedokun et al, 2008 and Golian et al., 2008). With the exception of one publication (Adedokun et al., 2007a) the results obtained for the basal endogenous loss with the NFD and REG methods were very comparable for most amino acids and were not significantly different. In the study of Adedokun et al. (2007a) the ileal endogenous flow was the same for the NFD and REG method at day 15, but were less comparable at day 21. At day 21 the ileal endogenous flows obtained with the REG method were numerically lower than those obtained with the NFD method, not only for total amino acids but also for the individual amino acids (with the exception of CYS). In three cases the differences were statistically significant. Detailed examination of their data showed that the lower losses obtained with the REG method were caused by a proportionally higher amino acid flow for the diet with highest casein level. Fitting lines through the data on the ileal flow of amino acids for the intermediate casein levels (5 and 10\%) gave values for the endogenous amino acid flows that were much closer to those found with the NFD diet than a linear regression through the data obtained for all three casein diets (5, 10 end 15\%). Despite the deviating results at day 21 , Adedokun et al. (2007a) concluded that the NFD and the regression method give similar results on day 15 and 21. This conclusion is supported by other studies of this group (Adedokun, 2007b, 2007c, 2008) and also by the study with broilers of Golian et al. (2008). Furuya and Kaji (1989) arrived to the same conclusion for pigs on this point.

Golian et al. (2008) compared the REG method using Casein and EHC as highly digestible protein sources. In addition they used a NFD. Using their data we determined the relation, by regression analysis, between the undigested amino acid flow and the percentage of protein source in the diet for all amino acids. The paper shows that the protein content of the casein and EHC used was almost equal (approx. 880 and $840 \mathrm{~g} / \mathrm{kg}$, respectively). The results are 
presented in Table 2 and, for some amino acids, in Figure 4. The results show very comparable basal endogenous losses with the NFD and the two REG methods.

Table 2. Basal endogenous flow (BEF) of amino acids (in $\mathrm{g} / \mathrm{kg} \mathrm{DMI}$ ) as determined by Golian et al. (2008), using a NFD and the REG method with two highly digestible protein sources (Casein and $E H C$, respectively). The regression equation for each amino acid was determined by ourselves according to the model $y=a x+c$, where $y=A A$ flow at terminal ileum, $x=$ percentage of Casein of EHC in diet, $a=$ coefficient of $x$ (slope of line) and $c=$ constant (intercept with $y$-axis, representing BEF according to the REG method). In the regression analysis all 4 diets $(0,5,10$ and $15 \%$ of protein source in diet) were used.

\begin{tabular}{|c|c|c|c|c|c|c|c|}
\hline \multirow{2}{*}{$\begin{array}{l}\text { Amino } \\
\text { Acid }\end{array}$} & \multirow{2}{*}{$\begin{array}{l}\text { BEF with } \\
\text { NFD method }\end{array}$} & \multicolumn{3}{|c|}{ Regression equation Casein data } & \multicolumn{3}{|c|}{ Regression equation EHC data } \\
\hline & & slope & Intercept & $\mathbf{R}^{2}$ & slope & Intercept & $\mathbf{R}^{2}$ \\
\hline ALA & 217 & 1.40 & 215 & 0.995 & 1.97 & 231 & 0.977 \\
\hline ARG & 203 & 0.47 & 197 & 0.899 & 0.94 & 204 & 0.988 \\
\hline ASP & 430 & 3.21 & 423 & 0.995 & 10.45 & 446 & 0.999 \\
\hline CYS & 143 & 0.34 & 142 & 0.982 & 0.42 & 145 & 0.953 \\
\hline GLU & 492 & 13.61 & 521 & 0.999 & 26.66 & 553 & 0.998 \\
\hline GLY & 245 & 0.89 & 243 & 0.977 & 1.49 & 252 & 0.987 \\
\hline HIS & 91 & 1.27 & 93 & 0.994 & 2.40 & 82.9 & 0.997 \\
\hline ILE & 200 & 4.40 & 211 & 0.997 & 2.40 & 236 & 0.923 \\
\hline LEU & 298 & 1.46 & 299 & 0.991 & 2.12 & 311 & 0.985 \\
\hline LYS & 173 & 1.81 & 177 & 0.994 & 1.87 & 178 & 0.994 \\
\hline MET & 65 & 0.79 & 68 & 0.981 & 0.82 & 67 & 0.998 \\
\hline PHE & 420 & 3.56 & 415 & 0.999 & 3.30 & 421 & 0.984 \\
\hline PRO & 289 & 2.09 & 281 & 0.995 & 9.67 & 296 & 1.000 \\
\hline SER & 343 & 7.30 & 359 & 0.999 & 6.55 & 413 & 0.961 \\
\hline THR & 434 & 2.55 & 427 & 0.996 & 3.63 & 452 & 0.991 \\
\hline TRP & 71 & 0.20 & 76 & 0.833 & 0.14 & 71 & 0.960 \\
\hline VAL & 270 & 2.79 & 274 & 0.997 & 2.22 & 291 & 0.971 \\
\hline Total AA & 4,368 & 47.52 & 4,463 & 0.998 & 77.10 & 4,640 & 0.995 \\
\hline
\end{tabular}
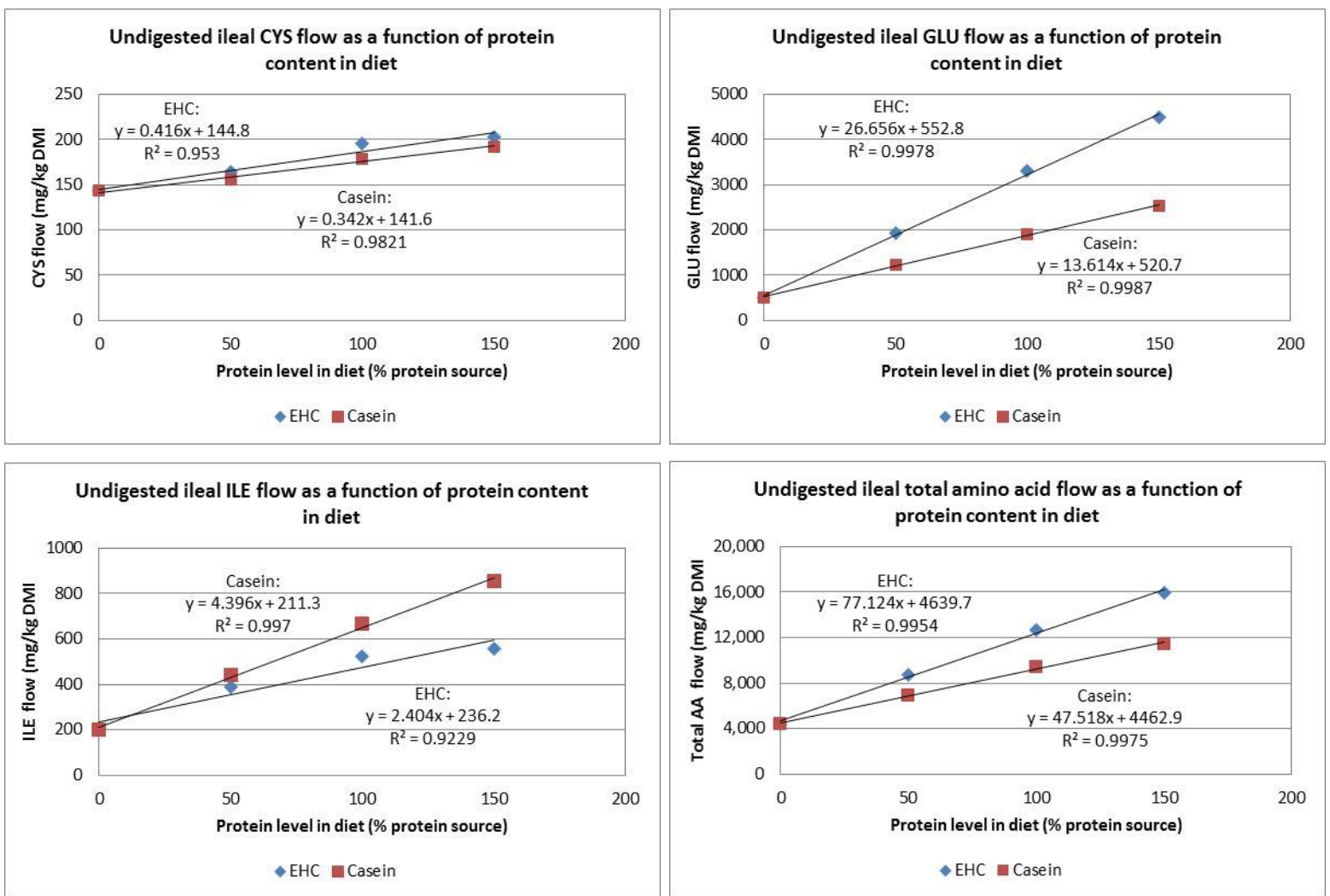

Figure 4. Undigested ileal amino acid flow as a function of the level of highly digestible protein sources in the diet (Casein and EHC, respectively) (Data from Golian et al., 2008). For some AA the flow is very similar for both protein sources, whereas for other AA there is a large difference. 
To see whether this, in the case of the REG method, is greatly caused by the fact that also the NFD was included in the regression analysis, we compared the basal endogenous losses obtained by regression analysis with and without the NFD diet. For some amino acids (CYS, GLU and THR) the results are presented in Figure 5. Omitting the NFD from the regression analysis resulted in an increase in the basal endogenous loss for some amino acids, and in a decrease for other amino acids.
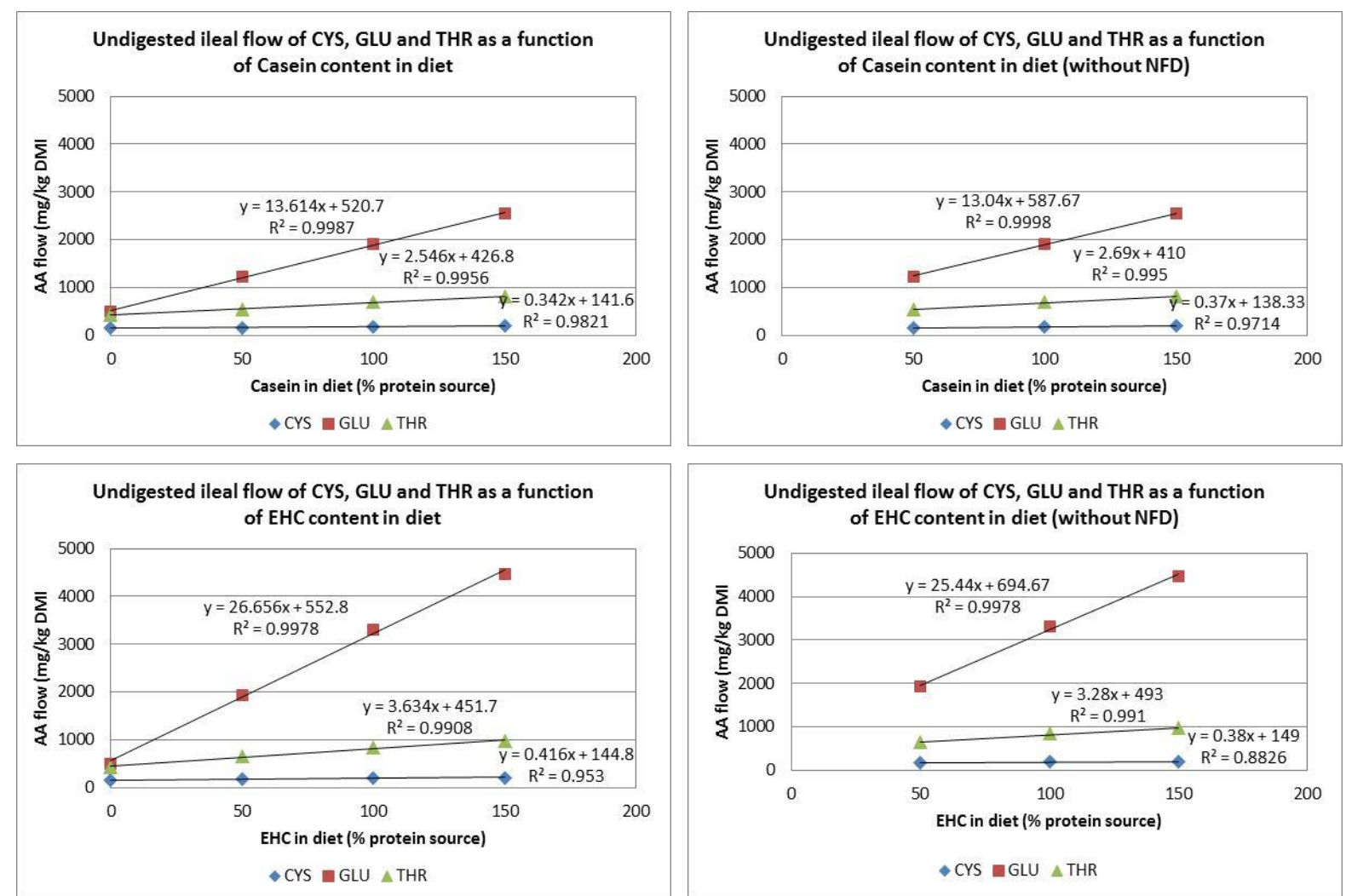

Figure 5. Undigested ileal flow of CYS, GLU and THR as a function of highly digestible protein source in the diet (upper figures Casein, lower figures EHC, respectively) (Data from Golian et al, 2008). In the left panels the regression equations are shown for the regression analysis including the NFD; in the right panels this diet was omitted from the analysis.

Another interesting point of the comparison of the two REG methods studied by Golian et al. (2008) (Table 2, Figure 4) is the difference in the slope of the regression lines. For 6 amino acids (ARG, ASP, GLU, GLY, HIS, PRO) and for total amino acids the slope of the regression line for the $\mathrm{EHC}$ diets was $>1.5$ times steeper than that for the Casein diets. For only one AA (ILE) the slope of the EHC diet was much less than that for the Casein diets, in other cases the slope was more or less comparable. This indicates that feeding a casein or an EHC diet results in different amino acid flows in the digesta at the terminal ileum. Golian et al. (2008) also published the amino acid composition of the Casein and EHC diets they used. As these patterns were very similar, the differences in ileal amino acid flow cannot be explained by differences in the amino acid composition of the diets. Maybe, the differences in the slope of the regression lines reflect the amino acid composition of the indigestible fraction of the protein source, which could imply that this fraction differs markedly between feeding an $\mathrm{EHC}$ or Casein diet.

\subsubsection{GuP (Guanidated Protein) method}

The GuP method to measure endogenous AA secretions usually comprises feeding a single meal containing GuP, following overnight food deprivation (Siriwan et al, 1994). This does not represent normal feeding conditions. It is assumed that homoarginine is transformed to lysine by arginase in the liver. However, it is suggested that this conversion is limited in 
chickens (Angkanaporn et al., 1997a). A lack of conversion of homoarginine into lysine may cause lysine deficiency. Guanidinated proteins may also have adverse effects on feed intake in chickens (Angkanaporn et al., 1997a).

lleal endogenous amino acid losses determined by the use of guanidinated casein are about twofold higher than those estimated either by feeding a N-free diet or by the REG method (Siriwan et al., 1994). After feeding EHC or GuP diets (both with CP levels of around 190 $\mathrm{g} / \mathrm{kg}$ ), Ravindran et al. (2004) in both cases found similar total ileal endogenous AA flows of 16.5 and $17.1 \mathrm{~g}$ per kg DMI, respectively. In their study, the NFD method resulted in a total ileal endogenous AA flow of only $5.8 \mathrm{~g}$ per kg DMI. Angkanaporn et al. (1997b) showed that endogenous amino acid losses in adult cockerels, as estimated using the GuP method, vary depending on protein source and dietary fibre concentration. This indicates that the GuP method yields basal plus diet specific endogenous amino acid losses, and not only basal endogenous amino acid losses.

As the GuP method gave results that strongly deviated from the results obtained with other methods (Siriwan et al., 1994) it was decided not to include these results in the calculation of a general profile of basal endogenous AA losses at ileal level in broilers in the present study.

\subsubsection{Effect of broiler age on endogenous losses}

Basal endogenous losses depend on the age of the birds (Adedokun et al., 2007a): at five days of age, basal endogenous losses are higher than at 15 or 21 days of age. The relatively low apparent amino acid digestibility coefficients for young chicks may be the result of a high endogenous amino acid flow. This is in line with findings of Makkink (1993) in young piglets: Using the ${ }^{15} \mathrm{~N}$ isotope dilution technique, she determined the apparent and true ileal protein digestibility of skimmilk powder, soybean meal, soy isolate and fishmeal. True ileal $\mathrm{N}$ digestibility was high (89 to $98 \%$ ) for all protein sources, but dietary soy and fish protein caused higher endogenous protein losses at the terminal ileum, resulting in lower apparent $\mathrm{N}$ digestibility values (73-78\%) than for skimmilk powder (84\%). Makkink concluded that young piglets are capable of digesting non-milk proteins to a high extent, however, they invest more in the digestive process - in terms of endogenous losses - than for the digestion of milk proteins.

At five days of age, the ileal endogenous flow of all amino acids as estimated using the REG method were significantly higher than values determined with $\mathrm{N}$-free feeding. With broilers aged 15 or 21 days, there were no differences between REG and NFD (Adedokun et al., 2007a). Toghyani et al. (2015) determined the endogenous nitrogen and amino acid flow in broiler chickens at 10 and 24 days of age, using $\mathrm{N}$-free diets, and reported significantly higher flows for $\mathrm{N}$ and most amino acids at 10 compared to 24 days of age.

Ravindran \& Hendriks (2004b) compared the ileal endogenous protein and amino acid flows of broilers aged 14 and 42 days, using diets with 18\% EHC. They found that ileal flow of nitrogen and amino acids were higher at 42 days of age, except for lysine and histidine (no age effect). The amino acid profile of ileal excreted protein did not differ between 14-day- and 42-day-old broilers.

Because of the age effects on basal endogenous $A A$ and $N$ losses reported in literature, we decided to exclude data obtained with chickens younger than 15 days from our further analyses and calculations.

\subsubsection{Effect of phytic acid and phytase on endogenous losses}

Singh (2008) and Cowieson et al. (2009) reviewed the literature on the influence of dietary phytate and phytase on endogenous nitrogen losses and nutrient availability.

Phytic acid forms complexes with protein and proteolytic enzymes (pepsin and trypsin). Phytate-bound nutrients are less accessible for digestion by poultry. Inclusion of graded concentrations of phytate- $P$ in the diet increased the flow of amino acids at the terminal ileum of broilers, as determined with the EHC-method. Cowieson et al. (2009) argued that the ingestion of phytate increased the secretion of intestinal and gastric mucin, leading to a higher concentration of endogenous peptides in the lower gut. 
Further, using the precision feeding assay, Cowieson et al. (2004) showed that the addition of phytate significantly increased the excretion of amino acids at the terminal ileum. Adding microbial phytase to plant-derived feed ingredients increased the apparent ileal digestibility of protein and amino acids (Singh, 2008). Cowieson et al. (2009) concluded that the beneficial influence of exogenous microbial phytase on amino acid and energy digestibility may be largely explained by a reduction of the antinutritive effects of phytate. lyayi (2013) studied the ileal digestibility of cowpeas in 21 day-old broilers in the absence and presence of exogenous phytase by using the REG method. As mentioned earlier, to our opinion the experimental set up of this study is not suitable to determine the basal endogenous AA flow. However, the study is suitable to study the effect of phytase. lyayi (2013) found that the intercept on the y-axis was numerically higher, but not significantly different, for $\mathrm{N}$ and all amino acids in the absence of phytase.

In diets that are most frequently used to determine the basal endogenous loss of amino acids (NFD, REG or HDP diets with casein or EHC) no phytate is present. So, the effects of phytate and phytase on endogenous secretions are not relevant for the determination of basal endogenous nutrient losses in broilers, but both affect the specific endogenous nutrient losses.

\subsubsection{General evaluation of the various methods to determine basal endogenous losses in broilers}

It has been stated that the protein-free diet method leads to a considerable underestimation of ileal endogenous amino acid flow in simple-stomached animals (Cowieson et al., 2009;:Lemme et al., 2004). To the opinion of Lemme et al. (2004) the EHC method is the preferred one, and they base the content and pattern of the basal endogenous protein loss solely on this method.

In our evaluation of the literature it was established that in both the HDP and the EHC method the amino acid flow at the terminal ileum is dependent on the protein level in the diet (Adedokun et al., 2007a, 2007c and 2008, Golian et al., 2008 an Ravindran et al., 2009). When highly digestible protein sources, e.g., casein or wheat gluten, are used, it is assumed that they do not induce significant amounts of specific endogenous proteins. This implies that the dose dependent increase of amino acid flow at the terminal ileum may reflect the undigested and unabsorbed fraction of the protein source. Even when the HDP induces a certain amount of specific endogenous protein, the method can be used to estimate the basal endogenous loss, provided that the specific endogenous protein loss is proportional to the inclusion of HDP in the diet. Golian et al. (2008) compared the Casein and EHC in the REG method. Using their results we showed that for a number of amino acids there is a remarkable difference between the two protein sources in the slope of the relationship between the terminal ileal amino acid flow and the protein level in the diet. As the amino acid of the Casein and EHC used in this study (Golian et al., 2008) was very similar, these differences cannot be attributed to different amino acid patterns in the diet, but more likely represent differences in the undigested fraction of the dietary protein.

Adedokun et al. (2007c, 2008) and Golian et al. (2008) found very similar endogenous losses using the REG method and the NFD method. In their studies there was a highly significant linear relationship between the terminal ileal amino acid flow and the protein level in the diet. When carefully looking to the results of another study of Adedokun et al. (2007a) we showed that the lower basal endogenous loss published by the authors for animals at 21 days of age using the REG method, could be fully attributed to a proportionally higher amino acid flow at the highest protein level, which was not observed in birds at day 15. Also Ravindran et al. (2009), using EHC as protein source, found a proportionally higher amino acid flow at the higher protein levels in the diet, especially at $20 \%$ EHC. In contrast, the significant quadratic relationship for some amino acids in the study of Golian et al. (2008) showed a decreasing augmentation of the amino acid flow at higher EHC levels in the diet. These fundamentally different responses require further investigation. 
As in many studies using the REG method also a NFD is investigated, the question is whether the NFD diet should be omitted from the regression analysis. We have explored the effect of the NFD on the basal endogenous loss obtained with the REG method for one study (Golian et al., 2008) and found that for some amino acids the endogenous flow increased slightly, whereas for others it decreased. As expected, it was also found that the accuracy of the estimation of the intercept of the $y$-axis was less when the NFD was not included in the regression analysis.

This confirmed that the accuracy of the estimation of the basal endogenous loss with the REG method depends on the distance between zero protein and the lowest protein level in the diet on the one hand and on the distance between the lowest and the highest protein level studies on the other hand.

A last comment concerning the HDP method using casein or other animal proteins is that the results are not obscured by possible protein - phytate interactions. This is also the case in studies using $\mathrm{EHC}$ or guanidated casein.

The observation that in a number of studies, using HDP or EHC, on the one hand the amino acid flow at the terminal ileum is dependent on the protein level in the diet, whereas on the other hand (very) comparable basal endogenous losses are found by using the REG and NFD method, implies that these two methods are most suitable to determine basal endogenous amino acid losses.

With respect to the HDP and EHC method, using one single diet with a certain level of casein or EHC, it should be concluded that in fact these methods are not suitable for the determination of the basal endogenous amino acid losses at the terminal ileum. However, at low casein or EHC levels the amino acid flows are only slightly and not significantly higher than in a NFD. Therefore, it was decided to use also the results of the HDP and EHC method for the determination of the basal endogenous loss, provided that the diets did not contain more than $50 \mathrm{~g} \mathrm{HDP}$ or EHC per $\mathrm{kg}$. At higher HDP levels the flow of amino acids in the digesta is affected too much by protein source in the diet.

A drawback of feeding NFD is that it, due to the absence of proteins, is principally a nonphysiological situation. Prolonged feeding of protein-free diets often causes higher endogenous losses of proline in pigs and poultry. Hodgkinson et al. (2000a) found a numeric but insignificant doubling in the mean proline secretion between day 1 and 8 of feeding a NFD and conclude 'that when the growing pig is fed a protein-free diet, there is no effect on endogenous ileal nitrogen or amino acid flow of the time the animal has received a proteinfree diet from between $30 \mathrm{~h}$ and 9 days, with the exception of the amino acids glycine and cysteine. When calculating the relative contribution of individual amino acids to endogenous ileal amino acid flow, the relative contribution was increased after feeding an $\mathrm{N}$-free diet for 8 days compared to 1 day, while the relative contribution of threonine, glycine and cysteine decreased (Hodgkinson et al., 2000a). Mariscal-Landín \& Reis de Souza (2006) found that a prolonged feeding of diets with low $\mathrm{N}$ level in piglets caused higher endogenous losses of proline (and glycine) in the digesta at the terminal ileum.

Also in poultry, the feeding of NFD sometimes induces an enhanced secretion of proline (e.g., Ravindran et al., 2009). It has been noticed already that this result is not easily to explain, when compared with other NFD studies (Golian et al., 2008, Adedokun et al. 2007c, 2008),

It is often suggested that the enhanced secretion of proline may be caused by disturbances in the protein metabolism. E.g., Mariscal-Landín \& Reis de Souza (2006) suggest that low N intake might induce an increase in body protein catabolism, which may cause an increased alanine and glutamine level in blood. Proline is synthesized from glutamine by erythrocytes. De Lange et al. (1989) observed that after feeding a $\mathrm{N}$-free diet to pigs of $60 \mathrm{~kg} \mathrm{BW}$ for 7 days approximately $30 \%$ of the endogenous protein consisted of proline. As in this study also the excretion of glycine was strongly enhanced the authors suggest the increase of endogenous protein in ileal digesta rich in proline and glycine probably resulted from a relatively large contribution of saliva and (or) bile to endogenous protein. According to Horowitz (1967) and Low (1982), glycoproteins excreted with bile and saliva contain relatively large amounts of proline and glycine. 
On the other hand it should be recognised that proline is also one of the most abundant amino acids in mucin. Of the glycosylated region of mucin polymers almost $90 \%$ consists of the amino acids proline, threonine and serine (Montagne \& Toullec, 2000). According to Forstner \& Forstner (1986), threonine and serine provide attachment sites for the oligosaccharide chains while proline may play a role in maintaining a particular conformation in the protein core, allowing carbohydrate chains to be packed very closely. In addition, Sauer and Ozimek (1986) suggested that fermentation of mucin by bacteria in the intestine would explain the considerably large intestinal disappearance of these amino acids.

Differences in secretion, digestion and fermentation of mucin may also play an important role in the flow of proline in the ileal digesta. However, taking into account the fact that mucin polypeptides that are rich in proline are also rich in threonine and serine, would indicate that an enhanced secretion of mucin would be accompanied by an increased secretion of these amino acids too.

Disturbances of protein metabolism with the NFD method may be avoided by applying parenteral infusion of a balanced solution of free amino acids to the animals during $\mathrm{N}$-free feeding (NFD-pi). This method was employed by De Lange et al. (1989) in pigs. They found that intravenous infusion of AA during $\mathrm{N}$-free feeding reduced the PRO content in the ileal digesta, suggesting that Pro metabolism could be maintained normal when applying AA infusion during $\mathrm{N}$-free feeding. However, no studies with poultry have been published applying the NFD-pi technique, likely because of difficult experimental execution with broilers.

In the literature references collected for the present desk study, no studies were found in which the effects were studied of the duration of $\mathrm{N}$-free feeding on the ileal amino acid losses (especially PRO).

High values for proline flow were sometimes found with NFD but also with EHC (see Appendix 1).

From Figure 2, left panel, it can be seen that PRO flow was considerably higher with the NFD method compared to the REG method.

Considering all studies concerning the flow of amino acids at the terminal ileum the following is concluded:

- There are no studies using the NFD with parenteral infusion of amino acids

- There are no studies using isotope dilution technique (e.g., ${ }^{15} \mathrm{~N}$-leucine)

- Studies using the Homoarginine technique or Guanidinated Protein method (GuP) are limited, and are not included in the proposed ileal AA flow in the present study because the basal endogenous flow determined by this method deviates considerably from that obtained with other methods.

- There is a large number of studies using the NFD method, also because NFD diets are often used in studies aiming to determine the standardised ileal amino acid digestibility of feed ingredients for poultry.

- There is a number of suitable studies using the REG method using graded levels of casein or $\mathrm{EHC}$ in the diets.

- Finally, there are few suitable studies using a single but low dose of a HDP (with casein as protein source) or EHC.

From the evaluation and discussion of the various methods in the previous sections it is concluded that, if proper executed, the NFD and REG method yield comparable and the most reliable results on the basal endogenous excretion of amino acids at the terminal ileum of broilers. As the use of NFD in practice is much easier than the REG method, we agree with Adedokun et al. (2011), who advice to use a N-free diet of standardized composition to estimate basal endogenous AA losses, although we suggest to use a higher starch:dextrose ratio compared to their recommendation.

Further, to calculate the AA composition of the basal ileal endogenous protein losses in broilers, only data of studies are used in the present desk study with broilers that have a minimum age of 15 days. 


\subsubsection{Summary of relevant literature data on the basal ileal flow of endogenous amino acids}

In the Annexes $1.1-1.4$ the data of individual studies are listed per method used.

For the NFD the number of observations is much higher than for other methods (see Annex 1.1). Because of the large number of data, it was decided the exclude outliers. This was done as follows: a) after calculating the mean flow of each amino acid and the standard deviation (STDEV), observations that deviated more than 3 times STDEV of the mean value were eliminated, b) after recalculating the mean value and standard deviation observations that deviated more than 2 times STDEV from the mean value were eliminated, after which the final mean value and standard deviation were calculated. The final results obtained for the NFD are listed in Table 3.

For the other methods the number of observations was considered too small to perform an outlier test. The results for the REG, HDP and EHC method are presented in Table 3 as well. Only experiments conducted with broilers aged 15 to 45 days have been included in this table.

Figure 6 summarizes literature data on the ileal endogenous flow determined with different experimental methods. Also in this graph only data from broiler studies have been included. It is clear that the EHC method yields a considerably higher flow of AA compared to the NFD or the REG method. The REG yields a flow that is comparable to results obtained with the NFD method. The HDP method yields intermediate results. With the EHC method, basal ileal endogenous AA flow is approximately twice as high as with the REG method. Especially the ileal endogenous flow of GLU is higher with the EHC and the HDP method. Because casein is rich in GLU (Li et al., 2011), this may be attributed to the presence of GLU rich residues at the terminal ileum when applying the EHC method or the HDP method using casein as highly digestible protein source.

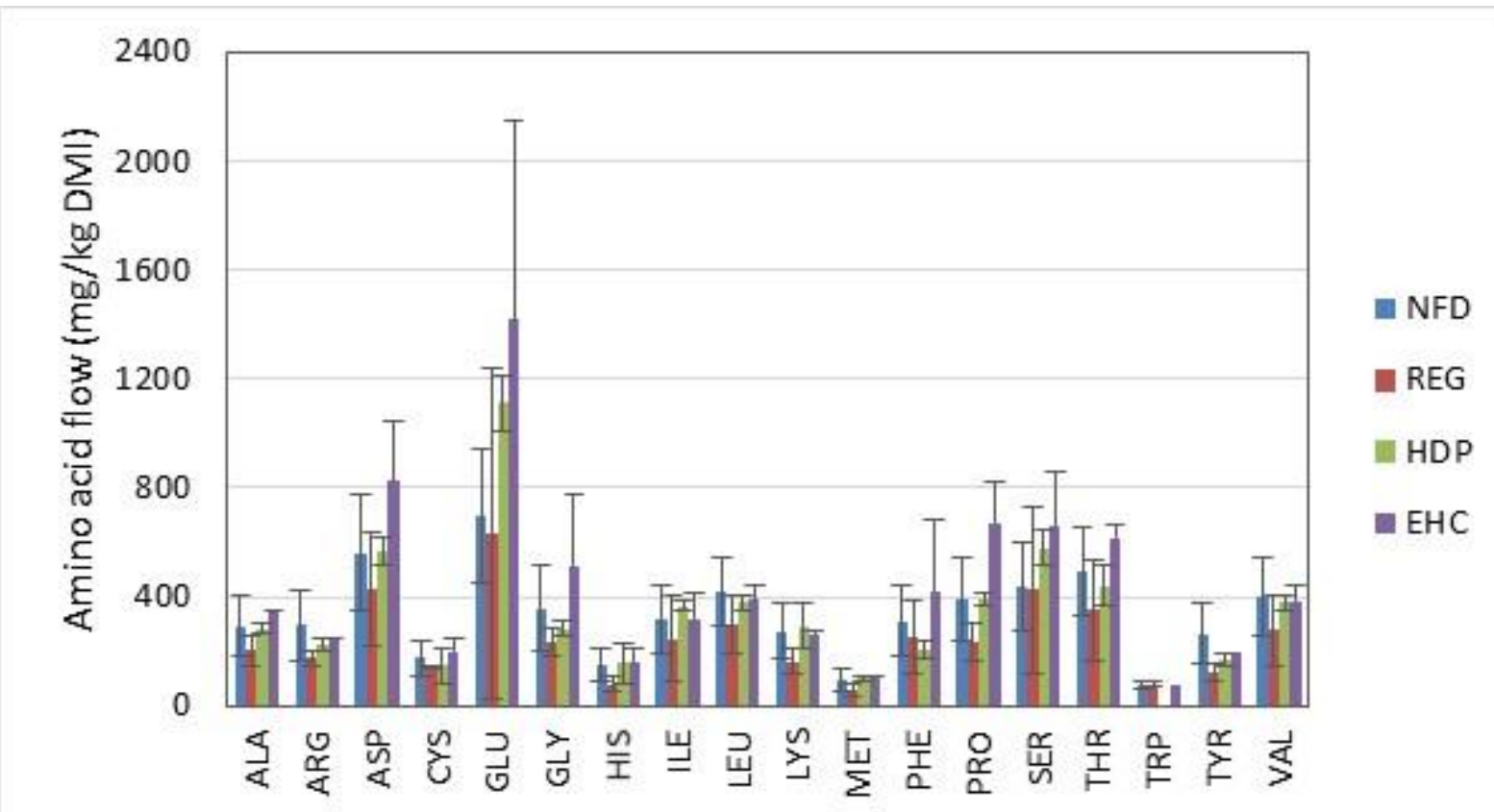

Figure 6. Ileal endogenous amino acid flow (mg per $\mathrm{kg}$ dry matter intake). Comparison of experimental methods (broilers). NFD: $n=29$, REG: $n=6$, HDP: $n=5 ; E H C: n=2$. Standard deviations are depicted by vertical arrow bars.

From Table 3 and Figure 6 it is clear that the standard deviation of the basal endogenous AA flow is rather high. As the number of observations per method is very different it is not possible to conclude which method yields the most consistent results. For all amino acids, basal endogenous ileal flow is higher with the EHC method as compared to the other methods. When calculating the relative standard deviation (= STDEV/Mean value*100) from the data presented in Table 3 , the highest values, indicative for the largest variation between 
studies, were found for the REG method. For this method the highest relative STDEV was found for GLU, for which the ileal flow ranged from 67 to $1780 \mathrm{mg} / \mathrm{kg}$ DMl (see also Annex 1.2). The standard deviation per amino acid for the four methods listed in Table 3 shows large differences between methods. Only for the amino acid PHE the relative STDEV was higher than $40 \%$ in three of the four methods.

Some studies in which the ileal endogenous flow of AA has been determined compare the use of different methods. Golian et al. (2008) found that the ileal endogenous flow of most amino acids were similar regardless of whether they were obtained by using the NFD or the REG method with EHC or casein. The same conclusion was drawn by Adedokun et al. comparing the ileal endogenous flow of AA by comparing the NFD method and the REG method using casein as only dietary protein source (Adedokun et al., 2007a; Adedokun et al. 2007c; Adedokun et al, 2008).

The flow of ileal endogenous protein in broilers as determined with the NFD and REG method - to our opinion the most reliable methods - were 6.9 and $4.6 \mathrm{~g}$ of amino acids per $\mathrm{kg}$ dry matter intake, respectively. This is substantially lower than in pigs $(8.2 \mathrm{~g}$ of amino acids per $\mathrm{kg}$ dry matter intake, $11.3 \mathrm{~g}$ CP per kg dry matter intake) (Jansman et al., 2002). When feeding NFD sometimes a strongly increased flow of Pro is observed, indicative of a perturbation of protein metabolism. When collecting data from studies using the NFD method, there was one study showing an extremely high flow of Pro (1070 mg per kg DMI, reported by Ravindran et al. (2009)) in broilers of 35 days of age after feeding a NFD for 4 days. In a database of 25 observations, this value deviated more than $3^{*}$ STDEV from the mean Pro flow of $418 \pm 200 \mathrm{mg} / \mathrm{kg} \mathrm{DMI}$. Therefore this value was eliminated as an outlier. After removing this value the mean flow of Pro decreased to $391 \pm 150 \mathrm{mg} / \mathrm{kg} \mathrm{DMl}$ with no observation deviating more than ${ }^{*}$ STDEV from the mean value.

As the number of observations per experimental method differs considerably, and as there still is a debate in the literature on the preferred method, it was decided to calculate an overall mean value over the methods considered, taking into account the number of observations per method:

- For each method the root square of the number of observations was calculated;

- The mean value per amino acid per method was calculated and multiplied by the root square of the number of observations for that method;

- The values obtained in this way for each amino acid and each method were added up over all methods;

- This sum was divided by the sum of the root squares of all methods, and resulted in mean values for the basal endogenous amino acid flow at ileal level (expressed in $\mathrm{mg} / \mathrm{kg}$ DMI). Values are given in Table 4.

The pattern shown in Figure 4 is used in the calculation of the standardized ileal digestibility of amino acids of ingredients for poultry.

Table 4. Basal endogenous flow of amino acids in broilers, ( $\mathrm{g} / \mathrm{kg} \mathrm{DMI})$ calculated as explained in the text.

\begin{tabular}{|l|c|c|c|}
\hline $\begin{array}{l}\text { Amino } \\
\text { acid }\end{array}$ & $\begin{array}{c}\text { Basal endogenous flow } \\
\text { (mg/kg DMI) }\end{array}$ & $\begin{array}{c}\text { Amino } \\
\text { acid }\end{array}$ & $\begin{array}{c}\text { Basal endogenous flow } \\
\text { (mg/kg DMI) }\end{array}$ \\
\hline ALA & 278 & LYS & 252 \\
\hline ARG & 250 & MET & 90 \\
\hline ASP & 568 & PHE & 289 \\
\hline CYS & 166 & PRO & 396 \\
\hline GLU & 856 & SER & 492 \\
\hline GLY & 336 & THR & 467 \\
\hline HIS & 138 & TRP & 78 \\
\hline ILE & 312 & TYR & 209 \\
\hline LEU & 379 & VAL & 367 \\
\hline Sum of all amino acids & & 5.920 \\
\hline
\end{tabular}


Table 3. Mean values for the basal flow of endogenous amino acids at the terminal ileum as determined by the NFD, REG, HDP and EHC method. For each method the number of observations, the mean amino acid flow and the standard deviation (in $\mathrm{mg} / \mathrm{kg} \mathrm{DMl}$ ) are presented after elimination of outliers as described in the text.

\begin{tabular}{|c|c|c|c|c|c|c|c|c|c|c|c|c|}
\hline \multirow{3}{*}{$\begin{array}{l}\text { Method } \\
n\end{array}$} & \multicolumn{3}{|c|}{ NFD } & \multicolumn{3}{|c|}{ REG } & \multicolumn{3}{|c|}{ HDP } & \multicolumn{3}{|c|}{$\mathrm{EHC}$} \\
\hline & $29 \mathrm{fr}$ & 25 publ & ions & $6 \mathrm{fr}$ & 4 public & ons & $5 \mathrm{frc}$ & 3 public & ons & $2 \mathrm{fr}$ & 2 public & \\
\hline & $\mathrm{n}$ per AA & mean & STDEV & $\mathrm{n}$ per AA & mean & STDEV & $\mathrm{n}$ per $\mathrm{AA}$ & mean & STDEV & $\mathrm{n}$ per $\mathrm{AA}$ & mean & STDEV \\
\hline ALA & 27 & 293 & 111 & 6 & 202 & 57 & 5 & 283 & 18 & 2 & 345 & 9 \\
\hline ARG & 28 & 295 & 133 & 6 & 174 & 25 & 5 & 228 & 23 & 2 & 247 & 2 \\
\hline ASP & 28 & 563 & 213 & 6 & 429 & 210 & 5 & 570 & 52 & 2 & 827 & 216 \\
\hline CYS & 23 & 176 & 65 & 5 & 141 & 7 & 5 & 149 & 66 & 2 & 200 & 50 \\
\hline GLU & 27 & 697 & 249 & 6 & 634 & 604 & 5 & 1112 & 104 & 2 & 1418 & 728 \\
\hline GLY & 29 & 358 & 158 & 6 & 235 & 49 & 5 & 283 & 26 & 2 & 515 & 260 \\
\hline HIS & 29 & 150 & 56 & 6 & 80 & 29 & 5 & 156 & 72 & 2 & 159 & 50 \\
\hline ILE & 29 & 318 & 129 & 6 & 244 & 158 & 5 & 367 & 19 & 2 & 317 & 100 \\
\hline LEU & 26 & 417 & 125 & 6 & 297 & 108 & 5 & 378 & 26 & 2 & 389 & 54 \\
\hline LYS & 26 & 274 & 106 & 6 & 163 & 49 & 5 & 293 & 80 & 2 & 263 & 16 \\
\hline MET & 27 & 95 & 44 & 6 & 58 & 24 & 5 & 100 & 8 & 2 & 110 & 1 \\
\hline $\mathrm{PHE}$ & 28 & 310 & 129 & 6 & 249 & 136 & 5 & 202 & 33 & 2 & 419 & 266 \\
\hline PRO & 24 & 391 & 150 & 5 & 235 & 68 & 5 & 393 & 25 & 2 & 671 & 156 \\
\hline SER & 29 & 440 & 161 & 6 & 426 & 308 & 5 & 580 & 64 & 2 & 664 & 200 \\
\hline THR & 29 & 491 & 164 & 6 & 353 & 186 & 5 & 438 & 74 & 2 & 616 & 46 \\
\hline TRP & 11 & 76 & 16 & 2 & 80 & 11 & 0 & & & 1 & 80 & \\
\hline TYR & 23 & 266 & 114 & 4 & 123 & 29 & 5 & 172 & 24 & 1 & 192 & \\
\hline VAL & 28 & 398 & 144 & 6 & 276 & 131 & 5 & 381 & 28 & 2 & 385 & 54 \\
\hline Total $\mathrm{AA}^{1}$ & 17 & 6804 & 3180 & 6 & 4570 & 1627 & 1 & 7713 & & 2 & 8462 & 379 \\
\hline
\end{tabular}

1 Total AA as given in the reference; in 'Total AA', other amino acids, such as taurine, are often included. Also, no publications were found that state 'Total AA' and all individual amino acids. 


\section{Composition of endogenous protein}

Endogenous protein consists of digestive enzymes, bile, mucoproteins and desquamated epithelial cells (Ravindran \& Hendriks, 2004b). These endogenous proteins are largely hydrolyzed and absorbed in the small intestine before reaching the terminal ileum (Souffrant et al., 1993). However, part of it passes the terminal ileum, and is lost as source of amino acids to the host.

The amino acid profile of ileal endogenous protein was not affected by age of the birds (14 or 42 days), suggesting that the relative proportions of the individual sources that contribute to endogenous protein are similar (Ravindran \& Hendriks, 2004b).

According to the literature, the composition of basal ileal endogenous protein ( $\mathrm{gAA} / 16 \mathrm{~g} \mathrm{~N})$ is less variable than the absolute basal ileal endogenous AA flow (mg/kg DMl): animal species, age, and experimental method hardly affect the AA composition of endogenous protein. According to Boisen and Moughan (1996), the composition of endogenous protein is relatively constant and does not relate to the ileal endogenous AA flow. Nevertheless, as data in the CVB table on amino acid digestibility of feed ingredients for poultry are based on observations with broilers, we only tabulated data on the amino acid composition of basal ileal endogenous protein in broilers in the present study.

The mean amino acid composition of basal endogenous CP ( $\mathrm{gAA} / 16 \mathrm{~g} \mathrm{~N})$ in ileal digesta of broilers from 11 publications is given in Table 5. To compile this table the same criteria were used as for the determination of the endogenous ileal amino acid flow, described in the previous section. This means that the minimum age of birds from which data were considered was 15 days, and that - in case of the HDP or EHC method - only data were used with a maximum inclusion level of casein or EHC of $5 \%$. Further, the amino acid composition either was published in the literature or was calculated from published data on the amino acid flow at the terminal ileum. To calculate the amino acid composition of the endogenous protein, the ileal flow of basal endogenous CP had to be published, in addition to values on the flow of individual amino acids. Unfortunately, in many publications values on the first were often missing. Sometimes the flow of total amino acids was given, however, it was decided not to use this figure for the further calculations on the amino acid composition of basal endogenous protein at ileal level. This implied that the number of observations on the amino acid composition of the endogenous protein is much less than that for the endogenous amino acid flow. Broiler age varied between 19 and 35 days. In total 15 results on the amino acid composition of basal endogenous protein were collected, 14 obtained with NFD and one derived from a study in which a 5\% EHC diet was fed. For detailed information see Appendix 2. In this annex data deviating more than two times the mean overall value, which are considered as outliers, are highlighted. In Table 5 the composition of the endogenous protein is given for the combined observations with NFD, for the observation with $\mathrm{EHC}$ and for all observations after eliminating outliers.

As can be seen from Table 5, the standard deviation in the amino acid content per $\mathrm{kg} \mathrm{CP}$ is rather high, even after eliminating outliers (= observations that deviated $>2 *$ STDEV from the mean). GLU is the most abundant amino acid in ileal basal endogenous protein, followed by ASP, THR, SER, LEU, PRO and GLY.

As there is only one observation with the EHC method included in Annex 2, it is difficult to judge whether results obtained with the EHC method provide different results compared to other methods. The figures found with the EHC method were within the range observed with the NFD method for all amino acids.

There are many more observations on the amino acid composition of protein in the digesta collected from the terminal ileum after feeding an EHC diet. However, the $\mathrm{EHC}$ inclusion rate was always higher than $5 \%$. The same is the case for the HDP method, using casein as protein source. Several studies have shown that the amino acid flow increases proportionally with the EHC or casein content of the diet (Golian et al., 2008; Ravindran et al, 2009). As 
these proteins do not contain anti-nutritional factors, it is more logic to assume that this increase is caused by an incomplete digestion of these protein sources than that is can be attributed to an increased loss of endogenous protein.

Cowieson et al. (2008) compared the amino acid composition of basal endogenous protein present in the digesta of diets with 10 and $20 \%$ EHC with the amino acids profile of pepsin and mucin and concluded that the composition of basal endogenous protein correlates well with that of these proteins.

Ravindran \& Bryden (1999) concluded from their literature review that ileal endogenous secretions in chickens contain high concentrations of AAP, SER and GLU. Porcine mucoproteins contain high concentrations of PRO, GLU, ASP, SER and THR (Lien et al., 1997). GLY, THR, SER, ASP and GLU seem to be absorbed more slowly from the gut lumen of pigs than other amino acids (Taverner et al., 1981). Assuming that the same is true for poultry, the results indicate that mucoproteins represent a large part of endogenous protein at the terminal ileum of poultry.

In pigs, bacterial proteins may be the largest single contributor to endogenous protein (Souffrant, 1991). Caine et al. (1999) found that in newly weaned piglets bacterial contribution to endogenous nitrogen recovery ranged from 30 to $46 \%$. Bacterial contributions to endogenous amino acids in ileal digesta were largest for ASP (36 to 48\%), GLU (55 to $66 \%$ ) and ARG (30 to 61\%). In bacterial isolates from ileal digesta of newly weaned piglets, GLU and ASP were the most abundant amino acids, followed by LEU, VAL and LYS. The content of HIS was lowest in these isolates (Caine et al., 1999). For poultry, no data were found concerning the microbial contribution to endogenous protein at the terminal ileum. As the intestinal tract of pigs contains more bacteria than the intestinal tract of poultry, it is, therefore, likely that the contribution of bacterial proteins to endogenous protein in the ileum is lower in poultry than in pigs. Fernández-Fígares et al. (2002) compared endogenous amino acids contents in ileal digesta and total tract excreta. They found similar ranking in terms of quantitative contribution of amino acids in endogenous protein at both sites. Total tract excretion of endogenous amino acids was lower than ileal excretion, indicating that microbiota in the hind gut utilize endogenous protein and deaminate amino acids.

In poultry, the contents of TRP, MET and HIS in endogenous protein were lowest compared to the other amino acids. The amino acid profile of ileal endogenous protein is relatively constant, as shown by the relatively low standard deviations compared to the standard deviations found with basal ileal endogenous AA flow (see Table 2).

Table 5. Mean AA composition of ileal endogenous crude protein $(6.25 \times \mathrm{N})$ in broilers (mean, SDTEV and number of observations) after eliminating outliers. For complete dataset see Annex 2.

\begin{tabular}{|c|c|c|c|c|c|c|c|c|c|}
\hline \multirow{2}{*}{$\begin{array}{l}\text { Amino } \\
\text { acid }\end{array}$} & \multicolumn{3}{|c|}{ All observations } & \multicolumn{3}{|c|}{ Observation with EHC } & \multicolumn{3}{|c|}{ Observations with NFD } \\
\hline & mean & std & $\mathbf{n}$ & mean & std & $\mathbf{n}$ & mean & std & $\mathbf{n}$ \\
\hline ALA & 38.9 & 5.5 & 15 & 42.9 & & 1 & 38.6 & 5.6 & 14 \\
\hline ARG & 37.5 & 8.6 & 15 & 30.0 & & 1 & 38.0 & 8.6 & 14 \\
\hline ASP & 72.7 & 10.3 & 14 & 82.3 & & 1 & 71.9 & 10.4 & 13 \\
\hline CYS & 28.7 & 22.8 & 14 & 28.6 & & 1 & 28.7 & 23.6 & 13 \\
\hline GLU & 94.0 & 22.3 & 14 & 110.0 & & 1 & 92.8 & 22.9 & 13 \\
\hline GLY & 45.5 & 15.1 & 14 & & & & 45.5 & 11.5 & 14 \\
\hline HIS & 17.3 & 6.0 & 14 & 15.1 & & 1 & 17.4 & 6.2 & 13 \\
\hline ILE & 37.4 & 7.5 & 14 & 30.0 & & 1 & 38.0 & 7.4 & 13 \\
\hline LEU & 54.8 & 11.6 & 15 & 42.7 & & 1 & 55.7 & 11.5 & 14 \\
\hline LYS & 35.4 & 11.2 & 14 & 30.7 & & 1 & 35.8 & 11.5 & 13 \\
\hline MET & 11.9 & 3.9 & 14 & 13.4 & & 1 & 11.8 & 4.1 & 13 \\
\hline PHE & 37.5 & 19.1 & 14 & 28.2 & & 1 & 38.2 & 19.4 & 13 \\
\hline PRO & 48.7 & 26.1 & 13 & 68.6 & & 1 & 47.0 & 26.9 & 12 \\
\hline SER & 54.7 & 13.4 & 14 & 63.7 & & 1 & 54.0 & 13.8 & 13 \\
\hline THR & 58.5 & 13.8 & 14 & 71.1 & & 1 & 57.5 & 14.0 & 13 \\
\hline TRP & 6.8 & 4.1 & 8 & & & & 6.8 & 4.1 & 8 \\
\hline TYR & 27.3 & 4.6 & 11 & 23.4 & & 1 & 27.7 & 4.6 & 10 \\
\hline VAL & 48.0 & 7.1 & 15 & 42.2 & & 1 & 48.4 & 7.2 & 14 \\
\hline
\end{tabular}


It was not possible to relate the AA composition of ileal endogenous CP (Table 5) directly to the basal ileal endogenous AA flow in poultry (Table 3), because flow data in literature do not include all amino acids, and basal ileal endogenous N or CP flow is not always provided. This is in contrast with the data collected by Jansman et al. (2002) for pigs.

Therefore, the basal endogenous flow in $\mathrm{mg} / \mathrm{kg}$ DMI was used to correct apparent amino acid digestibility values of feed ingredients for poultry to standardized digestibility values. 


\section{Discussion}

The use of more accurate and additive ileal digestibility values of amino acids for feed ingredients improves diet formulation for poultry and enables better matching of AA supply to AA requirements. Standardized ileal digestibility values provide more accurate and additive amino acid digestibility values, compared to apparent ileal digestibility values.

To estimate standardized ileal amino acid digestibility values of feed ingredients, the flow of basal ileal endogenous amino acids should be taken into account. Over the past decades, many studies have been published determining the endogenous ileal AA flow in poultry. The ileal endogenous AA losses may be determined with various experimental methods. With the NFD method, the duration of $\mathrm{N}$-free feeding should be limited, to avoid disturbances in protein metabolism. The period of $\mathrm{N}$-free feeding in the studies considered varied between three and eight days. With poultry, no studies were found in literature in which $\mathrm{N}$-free feeding was combined with parenteral infusion of a balanced mixture of free amino acids. No studies were found in which the time course of basal amino acid flow was studied nor was a consistent relationship found between the period of $\mathrm{N}$-free feeding and the flow of basal endogenous ileal AA.

Feeding enzymatically hydrolyzed casein $(E H C)$ or other highly digestible protein (HDP) sources causes an increase in ileal endogenous AA flow, depending on the level of EHC or HDP in the diet. Therefore, it appears that the EHC method and the HDP method are not suitable for determining basal ileal endogenous amino acid losses in poultry. Adedokun et al. (2011) derived the same conclusion from their review.

We found only two publications where the GuP method was used. With the GuP method, ileal endogenous amino acid losses were much higher than obtained with the NFD or the REG method. It seems that with the HDP method, the EHC method and the GuP method, total (basal and specific) endogenous AA losses are determined. Because standardized digestibility values should be calculated by taking into account only basal endogenous AA losses, we conclude that the $\mathrm{N}$-free diet and the regression method (REG) are the most valid procedures to estimate basal ileal endogenous amino acid losses in poultry. In the present desk study, the estimated flow of basal endogenous AA with the NFD and the REG method were comparable, while EHC and HDP methods, especially at higher inclusion rates of the protein sources used, seemed to overestimate basal flow of ileal endogenous AA. This is in contrast with Lemme et al. (2004) who concluded that the REG method overestimates basal flow, and only the EHC method yields a reliable estimation for basal endogenous AA flow. However, Adedokun et al. (2011) concluded from their literature study that the NFD method is the most consistent and reliable method for estimating basal endogenous AA flow. They recommend to use a standardised $\mathrm{N}$-free diet to establish basal endogenous amino acids flow in poultry.

The similarity we found between basal ileal endogenous AA flows determined using the REG and the NFD method is in agreement with the findings of Golian et al. (2008) and Adedokun et al. (2011).

Appendix 3 provides an overview of our proposal for the basal endogenous ileal AA flow, and the proposal given by Lemme et al. (2004).

For broilers, no studies were found in literature estimating the amino acid composition of basal endogenous ileal protein by means of the REG method. Also, data on the basal endogenous flow of $\mathrm{N}$ often is not provided in broiler studies using other methods. Therefore, it is not possible to use the approach that was taken by Jansman et al. (2002) for pigs to estimate basal endogenous AA flow in poultry. Jansman et al. (2002) combined the mean AA composition of basal endogenous CP $(\mathrm{g} / 16 \mathrm{~g} \mathrm{~N})$ with the mean values for the flow of basal endogenous ileal CP ( $\mathrm{g} / \mathrm{kg} \mathrm{DMI})$. 
For broilers, therefore, basal ileal endogenous AA flow was estimated directly from published data on basal ileal endogenous AA flow, as determined with various methods (NFD, REG and the HDP and EHC method, provided that low inclusion rates were used in the two latter cases).

All studies used to determine the basal endogenous AA loss in this report have been performed using growing broiler chicks, in which ileal digesta is collected at slaughter. Data obtained with other poultry categories (laying hens or cannulated adult roosters) are scarce. Data obtained with young chicks (age < 15 days) were not included in the present study, since ileal endogenous AA flows in young chickens differ markedly from those in older birds.

To calculate the basal endogenous amino acid flow studies were used performed with the NFD (29 observations from 25 publications), the REG method ( 6 observations from 4 publications), the HDP method (5 observations from 3 publications) and the EHC method (2 observations from 2 publications). Although the NFD and REG method are considered to give the most reliable results, also HDP studies with casein and EHC studies were included if the maximum inclusion rate of the protein source was $5 \%$. All studies were executed with broilers in the age of 15 to 45 days. As the number of studies per method varied largely a weighing factor taking into account the number of observations per method was used to calculate overall mean values (Table 5). From Table 5, we propose a total basal endogenous AA flow of 5.9 gram per $\mathrm{kg}$ DMI. The values for individual basal endogenous AA flow may be used to calculate standardized ileal amino acid digestibility from apparent ileal amino acid digestibility of feedstuffs for broilers. Caution is warranted when applying the proposed basal ileal endogenous amino acid flow to calculate the standardized ileal amino acid digestibility for young chickens (below 15 days), since the flow of basal endogenous AA is likely higher in young chicks. This age effect should also be taken into account when calculating and recommending $A A$ requirement values for young broilers expressed on a standardized ileal digestible basis. 


\section{Conclusions}

Experimental method, age and category of birds, and phytate and/or phytase content of diets influence the ileal endogenous AA flow in poultry.

Based on our literature study, we conclude that the NFD and the REG method are most suitable to estimate basal ileal endogenous AA losses in broilers. Other methods seem to include specific AA losses, affected by the type of protein or the dietary composition, whereas basal losses should only depend on dry matter intake..

Because of the abundance of broiler data, it is feasible to estimate basal ileal endogenous AA flows in broilers. Data obtained with young chicks (age 14 days or less) should be discarded, since ileal endogenous AA flows in young chicks differ markedly from those in older broilers.

Basal endogenous ileal $\mathrm{N}$ flow was not reported in most broiler studies. Therefore, we could not take the same approach as Jansman et al. (2002) did for pigs. We estimated the basal ileal endogenous AA flow in poultry from published studies using the NFD method, the REG method and the HDP and EHC method (provided that the protein source was incorporated at a low level) in broiler chickens age 15 to 45 days. The basal ileal endogenous flow of total amino acids amounts to $5.90 \mathrm{~g}$ per $\mathrm{kg}$ dry matter intake. The values for the basal ileal endogenous flow of individual amino acids may be used to calculate standardized ileal amino acid digestibility from apparent ileal amino acid digestibility of feedstuffs for poultry. 


\section{References}

Adedokun, S.A., O. Adeola, C.M. Parsons, M.S. Lilburn \& T.J. Applegate; 2011

Factors affecting endogenous amino acid flow in chickens and the need for consistency in methodology. Poultry Science 90:1737-1748

Adedokun, S.A., C.M. Parsons, M.S. Lilburn, O. Adeola \& T.J. Applegate; 2007a Endogenous amino acid flow in broiler chicks is affected by the age of birds and method of estimation. Poultry Science 86:2590-2597

Adedokun, S.A., C.M. Parsons, M.S. Lilburn, O. Adeola \& T.J. Applegate; 2007b Standardized ileal amino acid digestibility of meat and bone meal from different sources in broiler chicks and turkey poults with a nitrogen-free or casein diet. Poultry Science 86:2598-2607

Adedokun, S.A., C.M. Parsons, M.S. Lilburn, O. Adeola \& T.J. Applegate; 2007c Comparison of ileal endogenous amino acid flows in broiler chicks and turkey poults. Poultry Science 86:1682-1689

Adedokun, S.A., O. Adeola, C.M. Parsons, M.S. Lilburn, \& T.J. Applegate; 2008 Standardized ileal amino acid digestibility of plant feedstuffs in broiler chickens and turkey poults using a nitrogen-free or casein diet. Poultry Science 87:2535-2548

Angkanaporn, K., V. Ravindran, \& W.L. Bryden; 1996 Additivity of apparent and true ileal amino acid digestibilities in soybean meal, sunflower meal, and meat and bone meal for broilers. Poultry Sci. 75:1098-1103

Angkanaporn, K., V. Ravindran, Y. Mollah, \& W.L. Bryden; 1997a Homoarginine influences voluntary feed intake, tissue basic amino acid concentrations and arginase activity in chickens. J. Nutr. 127:1128-1136

Angkanaporn, K., V. Ravindran, Y. Mollah, \& W.L. Bryden; 1997b Evaluation of homoarginine as a marker for the determination of endogenous amino acid concentrations in poultry excreta. Br. Poultry Sci. 38:577-585

Bandegan, A., E. Kiarie, R.L. Payne, G.H. Crow, W. Guenter, \& C.M. Nyachoti; 2010 Standardized ileal amino acid digestibility in dry-extruded expelled soybean meal, extruded canola seed-pea, feather meal, and poultry meal for broiler chickens. Poultry Science 89:2626-2633

Boisen, S., \& P.J. Moughan; 1996 Dietary influences on endogenous ileal protein and amino acid loss in the pig - a review. Acta Agric. Scand., Sect. A, Anim. Sci. 46:154-164

Bryden, W.L., X. Li, G. Ravindran, L.I. Hew \& V. Ravindran; 2009 Ileal digestible amino acids in feedstuffs for poultry. Values in Feedstuffs for poultry. Rural Industries Research \& Development Corporation. RIRDC Publication No 09/71.

Caine, W.R., S. Tamminga, W.C. Sauer, M.W.A. Verstegen \& H. Schulze; 1999 Bacterial contributions to total and endogenous recoveries of nitrogen and amino acids in ileal digesta of newly weaned piglets fed protease-treated soybean meal. Livest. Prod. Sci. $57: 147-157$

Claustre, J., F. Toumi, A. Trompette, G. Jourdan, H. Guignard, J.A. Chayvialle \& P. Plaisance; 2002.

Effects of peptides derived from dietary proteins on mucus secretion in rat jejunum. Am. J. Physiol. Gastrointest. Liver Physiol. 283:521-528

Cowieson, A.J., \& V. Ravindran; 2007 Effect of phytic acid and microbial phytase on the flow and amino acid composition of endogenous protein at the terminal ileum of growing broiler chickens. Br. J. Nutr. 98:745-752

Cowieson, A.J., V. Ravindran \& P.H. Selle; 2008 Influence of dietary phytic acid and source of microbial phytase on ileal endogenous amino acid flows in broiler chickens. Poultry Science 87:2287-2299

Cowieson, A.J., M.R. Bedford, P.H. Selle \& V. Ravindran; 2009 Phytate and microbial phytase: implications for endogenous nitrogen losses and nutrient availability. World's Poultry Science Journal 65:401-417

Dalibard, P., \& E. Paillard; 1995 
Use of the digestible amino acid concept in formulating diets for poultry. Anim. Feed Sci. Technol. 53(2):189-204

Deglaire, A., P.J. Moughan, S.M. Rutherfurd, C. Bos \& D. Tomé; 2007

Feeding dietary peptides to growing rats enhances gut endogenous protein flows compared with feeding protein-free or free amino acid-based diets. J. Nutr. 137:24312436

Deglaire, A., P.J. Moughan, C. Bos, K. Petzke, S.M. Rutherfurd, \& D. Tomé; 2008 A casein hydrolysate does not enhance gut endogenous protein flows compared with intact casein when fed to growing rats. J. Nutr. 138:556-561

Fernández-Fígares, I., R. Nietao, C. Prieto \& J.F. Aguilera; 2002 Estimation of endogenous amino acid losses in growing chickens given soya-bean meal supplemented or not with DL-methionine. Anim. Sci. 75:415-426

Forstner G.G., Forstner J.F., 1986.

Structure and function of gastrointestinal mucus. In: P. Desneulle, H. Sjostrom, O. Noren (Editors). Molecular and Cellular Basis of Digestion. Elsevier Science Publishers B.V. (Netherlands), pp. 125-143

Furuya, S. and Kaji, Y; 1989.

Estimation of the true ileal digestibility of amino acids and nitrogen from their apparent values for growing pigs. Animal Feed Science and Technology 26:271-285.

Golian, A., W. Guenter, D. Hoehler, H. Jahanian \& C.M. Nyachoti; 2008 Comparison of various methods for endogenous ileal amino acid flow determination in broiler chickens. Poultry Science 87:706-712

Hagemeister, H. \& H. Erbersdobler; 1985

Chemical labelling of dietary protein by transformation of lysine to homoarginine: a new technique to follow intestinal digestion and absorption. Proceedings of the Nutrition Society $44: 133 \mathrm{~A}$

Hodgkinson, S.M., P.J. Moughan, G.W. Reynolds; 2000a.

Effect of the duration of feeding of a protein-free diet on endogenous ileal nitrogen and amino acid loss in the growing pig. J. Sci. Food Agric. 80:1407-1412

Hodgkinson, S.M., P.J. Moughan, G.W. Reynolds \& K.A.C. James; $2000 \mathrm{~b}$. The effect of dietary peptide concentration on endogenous ileal amino acid loss in the growing pig. Br. J. Nutr. 83(4):421-430

Honda, K., H. Kamisoyama, S. Kubo, T. Motoori \& S. Hasegawa; 2010.

Effects of dietary fat levels on amino acid digestibility at different sites of chicken intestines. J. Poult. Sci. 47:227-235

Horowitz, M. I., 1967.

Mucopolysaccharides and glycoproteins of the alimentary tract. In: Code C. F. (ed.).

Handbook of Physiology, Section 6, Vol II. American Physiological Society,

Washington, DC, pp. 1063-1085.

Huang, K.H., X. Li, V. Ravindran \& W.L. Bryden; 2006.

Comparison of apparent ileal amino acid digestibility of feed ingredients measured with broilers, layers, and roosters. Poultry Science 85:625-634

Hulan, H.W., \& F.H. Bird; 1972

Effect of fat level in isonitrogenous diets on the composition of avian pancreatic juice. J. Nutr. 102:459-468

lyayi, E.A.; 2013.

Effect of phytase supplementation on the digestibility of crude protein, amino acids and phosphorus of cowpea (Vignia unguiculata) in broilers. International Journal Poultry Science 12: 45-50.

Jansman, A.J.M., W. Smink, P. van Leeuwen \& M. Rademacher; 2002.

Evaluation through literature data of the amount of basal endogenous crude protein at the terminal ileum of pigs. Animal Feed Science and Technology 98:49-60

Kadim, I.T., P.J. Moughan \& V. Ravindran; 2002.

Ileal amino acid digestibility assay for the growing meat chicken - comparison of ileal and excreta amino acid digestibility in the chicken. British Poultry Science 44:588-597

Lange, C.F.M. de, W.C. Sauer, R. Mosenthin \& W.B. Souffrant; 1989. 
The effect of feeding different protein free diets on the recovery and amino acid composition of endogenous protein collected from the distal ileum and feces in pigs. J. Anim. Sci. 67:746-754

Lemme, A., V. Ravindran \& W.L. Bryden; 2004.

Ileal digestibility of amino acids in feed ingredients for broilers. World's Poultry Science Journal 60:423-438

Li, X., R. Rezaei, P. Li \& G. Wu; 2011.

Composition of amino acids in feed ingredients for animal diets. Amino Acids 40(4):1159-1168

Lien, K.A., W.A. Sauer \& M. Fenton; 1997

Mucin output in ileal digesta of pigs fed a protein-free diet. J. Anim. Sci. 72:1737-1743

Low, A. G.; 1982.

Endogenous nitrogen evaluation from absorption studies. In: Physiology digestive chez le porq, Jouy-en-Josas. Les Colloques de I'INRA 12:189.

Makkink, C.A.; 1993

Of piglets, dietary proteins, and pancreatic proteases. $\mathrm{PhD}$ thesis Wageningen

University; ISBN 90-5485-104-X

Mariscal-Landín, G. \& T.C. Reis de Souza; 2006

Endogenous ileal losses of nitrogen and amino acids in pigs and piglets fed graded levels of casein. Archives of Animal Nutrition 60(6):454-466

Milner-Williams, W., P.J. Moughan \& M.F. Fuller; 2009

Endogenous components of digesta protein from the terminal ileum of pigs fed a casein-based diet. J. Agric. Food Chem. 57:2072-2078

Moughan, P.J., C.A. Butts, A.M. Rowan \& A. Deglaire; 2005

Dietary peptides increase endogenous amino acid losses from the gut in adults. Am. J.

Clin. Nutr. 81:1359-1365

Montagne, L. and Toullec, R; 2000

Influence of dietary protein level and origin on the flow of mucin along the small

intestine of the preruminant calf. J. Dairy Sci. 83 (12), 2820-2828).

Opapeju, F.O., A. Golian, C.M. Nyachoti \& L.D. Campbell; 2006

Amino acid digestibility in dry extruded-expelled soybean meal fed to pigs and poultry. Journal of Animal Science 84:1130-1137

Parsons, C.M.; 1996

Digestible amino acids for poultry and swine. Anim. Feed Sci. Technol. 59(1-3):147153

Pérez, L., I. Fernández-Fígares, R. Nieto, J.F. Aguilera \& C. Prieto; 1993

Amino acid ileal digestibility of some grain legume seeds in growing chickens. Anim.

Prod. 56:261-267

Ravindran, V., \& W.L. Bryden; 1999

Amino acid availability in poultry - in vitro and in vivo measurements. Australian J. Agric. Res. 50(5):889-908

Ravindran, V., \& W.H. Hendriks; 2004a

Endogenous amino acid flows at the terminal ileum of broilers, layers and adult roosters. Anim. Sci. 79:265-271

Ravindran, V., \& W.H. Hendriks; 2004b

Recovery and composition of endogenous protein collected at the terminal ileum as influenced by the age of broiler chickens. Australian Journal of Agricultural Research 55:705-709

Ravindran, V., L.I. Hew, G. Ravindran \& W.L. Bryden; 1999

A comparison of ileal and excreta analysis for the determination of amino acid

digestibility in food ingredients for poultry. British Poultry Science 40(2):266-274

Ravindran, V., L.I. Hew, G. Ravindran \& W.L. Bryden; 2004

Endogenous amino acid flow in the avian ileum: quantification using three techniques.

British Journal of Nutrition 92:217-223

Ravindran, V., P.C.H. Morel, S.M. Rutherford \& D.V. Thomas; 2009 
Endogenous flow of amino acids in the avian ileum as influenced by increasing dietary peptide concentrations. British Journal of Nutrition 101:822-828

Rostagno, H.S., J.M.R. Pupa \& M. Pack ; 1995

Diet formulation for broilers based on total versus digestible amino acids. J. Appl.

Poultry Res. 4(3):293-299

Rutherford, S.M., T.K. Chung \& P.J. Moughan; 2002

The effect of microbial phytase on ileal phosphorus and amino acid digestibility in the broiler chicken. Br. Poultry Sci. 44:598-606

Sauer, W.C. and Ozimek, L.; 1986.

Digestibility of amino acids in swine: results and their practical applications. A Review. Livestock Production Science 15: 367-388.

Singh, P.K.; 2008

Significance of phytic acid and supplemented phytase in chicken nutrition: a review. World's Poultry Science Journal 64:553-580

Siriwan, P., W.L. Bryden, Y. Mollah \& E.F. Annison; 1993

Measurement of endogenous amino acid losses in poultry. Br. Poultry Sci. 34:939-949

Siriwan, P., W.L. Bryden, \& E.F. Annison; 1994

Use of guanidinated protein to measure losses of endogenous amino acid in poultry.

Br. J. Nutr. 71:515-529

Souffrant, W.B.; 1991

Endogenous nitrogen losses during digestion in pigs. In: Verstegen, M.W.A., J. Huisman \& L.A. den Hartog (Eds). Digestive Physiology in Pigs. EAAP Publication No 54, PUDOC, Wageningen, The Netherlands. Page 147-166

Souffrant, W.B, A. Rérat, J.P. Laplace, B. Darcy-Vrillon, R. Köhler, T. Corring \& G.

Gebhardt ; 1993

Exogenous and endogenous contributions to nitrogen fluxes in the digestive tract of pigs fed a casein diet. III. Recycling of endogenous nitrogen. Reprod. Nutr. Develop. 33:373-382

Stein, H., C. Pedersen, A. Wirt, \& R. Bohlke, 2005

Additivity of values for apparent and standardized ileal digestibility of amino acids in mixed diets for growing pigs. J. Anim. Sci. 83:2387-2395

Taverner, M.R., I.D. Hume \& D.J. Farrell; 1981

Availability to pigs of amino acids in cereal grains. I. Endogenous levels of amino acids in ileal digesta and faeces of pigs given cereal diets. Br. J. Nutr. 46:149-158

Valencia, D.G., M.P. Serrano, E. Jiménez-Moreno, R. Lázaro \& G.G. Mateos ; 2009 Ileal digestibility of amino acids of pea protein concentrate and soya protein sources in broiler chicks. Livest. Sci. 121:21-27

Wiliams, P.E.V.; 1995

Digestible amino acids for non-ruminant animals: theory and recent challenges. Anim. Feed Sci. Technol. 53(2):173-187

Woyengo, T.A., E. Kiarie \& C.M. Nyachoti; 2010 Metabolizable anergy and standardized ileal digestible amino acids contents of expeller-extracted canola meal fed to broiler chicks. Poultry Sci. 89:1182-1189

Zhang, H.L., S.Y. Qiao, X.J. Chen, X. Wang, J.J. Xing \& Y.L. Yin; 2005 Effects of graded levels of soya-bean protein on endogenous ileal lysine loss and amino acid digestibility in growing pigs. Anim. Sci. 81:85-97 


\section{Appendix 1. Literature data on endogenous ileal AA flow in broilers.}

Essential amino acids: Arg, His, lle, Leu, Lys, Met, Phe, Thr, Trp, Val. Nonessential amino acids: Ala, Asp, Cys, Glu, Gly, Pro, Ser, Tyr (Ravindran \& Bryden, 1999).

\subsection{Results for NFD (Nitrogen Free Diets)}

For each amino acid, total $A A$ and $C P$ an outlier analysis was done: first data deviating $\geq 3{ }^{*} S T D E V$ from the mean value were eliminated; subsequently, the mean value and STDEV were recalculated and data $\geq 2 *$ STDEV from the mean value were eliminated; finally, the mean and STDEV were calculated; these data are presented in the table below.

\begin{tabular}{|c|c|c|c|c|c|c|c|c|c|c|c|c|c|c|c|c|c|c|c|c|c|c|}
\hline Ref & Age (d) & $\begin{array}{r}\text { Year of } \\
\text { publication }\end{array}$ & ALA & ARG & ASP & CYS & GLU & GLY & HIS & ILE & LEU & LYS & MET & PHE & PRO & SER & THR & TRP & TYR & VAL & $\begin{array}{l}\text { Total } \\
\text { AA 1) }\end{array}$ & $\mathbf{C P}$ \\
\hline 1 & 15 & 2007 & 170 & 156 & 337 & 115 & 383 & 195 & 71 & 153 & 241 & 178 & 51 & 154 & 215 & 230 & 274 & 6 & 116 & 205 & 3730 & 6 \\
\hline 1 & 21 & 2007 & 177 & 168 & 340 & 136 & 420 & 205 & 73 & 162 & 251 & 181 & 50 & 154 & 240 & 260 & 274 & 6 & 124 & 214 & 3952 & 6 \\
\hline 2 & 15 & 2007 & 186 & 179 & 382 & 132 & 430 & 219 & 81 & 174 & 276 & 209 & 56 & 183 & 250 & 261 & 297 & 6 & 144 & 232 & 4242 & 6 \\
\hline 2 & 21 & 2007 & 167 & 159 & 329 & 138 & 431 & 195 & 70 & 159 & 242 & 182 & 44 & 153 & 245 & 268 & 263 & 6 & 130 & 205 & 3935 & 6 \\
\hline 3 & 21 & 2009 & 140 & 122 & 248 & 87 & 334 & 155 & 57 & 119 & 184 & 140 & 50 & 119 & 163 & 169 & 236 & 6 & 98 & 180 & 3076 & 6 \\
\hline 4 & 21 & 2014 & 388 & 389 & 722 & 240 & 926 & 454 & 154 & 343 & 567 & 345 & 107 & 7 & 488 & 556 & 557 & 6 & 6 & 456 & 6 & 6 \\
\hline 5 & 28 & 2015 & 294 & 269 & 445 & 114 & 770 & 313 & 204 & 253 & 445 & 308 & 121 & 296 & 344 & 353 & 298 & 6 & 263 & 324 & 6 & 6 \\
\hline 6 & 21 & 2008 & 217 & 203 & 430 & 143 & 492 & 245 & 91 & 200 & 298 & 173 & 65 & 420 & 289 & 343 & 434 & 71 & 6 & 270 & 4368 & 6 \\
\hline 7 & 39 & 2002 & 510 & 480 & 600 & 6 & 740 & 440 & 180 & 440 & 520 & 420 & 190 & 410 & 500 & 730 & 730 & 6 & 390 & 530 & 6 & 6 \\
\hline 8 & 21 & 2011 & 303 & 340 & 731 & 375 & 888 & 369 & 167 & 463 & 424 & 358 & 7) & 162 & 456 & 479 & 629 & 85 & 287 & 400 & 6 & 6 \\
\hline 9 & $26^{2)}$ & 2013 & 8) & 575 & 1015 & 8) & 8) & 653 & 248 & 541 & 8) & 8) & 173 & 500 & 675 & 711 & 804 & 68 & 390 & 660 & 12779 & 6 \\
\hline 9 & $\left.26{ }^{3}\right)$ & 2013 & 8) & 8) & 8) & 8) & 8) & 666 & 256 & 556 & 8) & 8) & 172 & 523 & 655 & 708 & 772 & 74 & 402 & 674 & 12692 & 6 \\
\hline 9 & $26^{4)}$ & 2013 & 550 & 586 & 1023 & 8) & 1314 & 627 & 248 & 533 & 8) & 8) & 177 & 511 & 628 & 680 & 728 & 70 & 395 & 648 & 12109 & 6 \\
\hline 10 & 19 & 2013 & 377 & 369 & 752 & 218 & 915 & 431 & 160 & 375 & 564 & 382 & 100 & 345 & 519 & 505 & 582 & 87 & 287 & 531 & 8763 & 12244 \\
\hline 11 & 19 & 2013 & 373 & 351 & 741 & 228 & 844 & 384 & 146 & 356 & 539 & 374 & 86 & 323 & 415 & 529 & 577 & 52 & 279 & 509 & 7828 & 11744 \\
\hline 12 & 37 & 2004 & 293 & 280 & 607 & 226 & 721 & 508 & 158 & 287 & 439 & 209 & 101 & 287 & 6) & 424 & 512 & 95 & 253 & 417 & 5817 & 6 \\
\hline 13 & 37 & 9 & 292 & 238 & 549 & 201 & 689 & 477 & 133 & 252 & 363 & 225 & 89 & 195 & 9) & 414 & 527 & 6 & 206 & 282 & 6201 & 6 \\
\hline 14 & 34 & 2014 & 370 & 370 & 590 & 220 & 870 & 620 & 170 & 340 & 510 & 290 & 100 & 260 & 330 & 520 & 600 & 6 & 280 & 450 & 8160 & 6 \\
\hline 15 & 28 & 2017 & 480 & 490 & 840 & 250 & 1110 & 500 & 200 & 420 & 690 & 520 & 160 & 490 & 550 & 630 & 620 & 7 & 550 & 6 & 6 & 12290 \\
\hline 16 & 29 & 1992 & 252 & 66 & 253 & 155 & 539 & 117 & 148 & 194 & 394 & 73 & 65 & 180 & 137 & 302 & 295 & 7 & 163 & 245 & 6 & 5090 \\
\hline 17 & 40 & 1993 & 250 & 230 & 490 & 6 & 630 & 280 & 100 & 390 & 490 & 220 & 70 & 250 & 6) & 390 & 450 & 6 & 7 & 370 & 6 & 6 \\
\hline 18 & $35-45^{5)}$ & 1994 & 270 & 250 & 610 & 6 & 740 & 290 & 140 & 200 & 470 & 240 & 70 & 290 & 6) & 510 & 540 & 6 & 320 & 420 & 5360 & 6 \\
\hline 19 & $42^{5)}$ & 2010 & 349 & 469 & 574 & 103 & 851 & 400 & 203 & 327 & 535 & 383 & 81 & 394 & 341 & 547 & 538 & 50 & 265 & 398 & 6810 & 959 \\
\hline 20 & 30 & 2009 & 229 & 282 & 578 & 104 & 752 & 284 & 211 & 288 & 498 & 270 & 89 & 283 & 465 & 382 & 299 & 101 & 361 & 378 & 5854 & 6 \\
\hline
\end{tabular}




\begin{tabular}{|c|c|c|c|c|c|c|c|c|c|c|c|c|c|c|c|c|c|c|c|c|c|c|}
\hline Ref & Age (d) & $\begin{array}{r}\text { Year of } \\
\text { publication }\end{array}$ & ALA & ARG & ASP & CYS & GLU & GLY & HIS & ILE & LEU & LYS & MET & PHE & PRO & SER & THR & TRP & TYR & VAL & $\begin{array}{l}\text { Total } \\
\text { AA 1) }\end{array}$ & CP \\
\hline 22 & 10 & 2015 & 296 & 92 & 633 & 191 & 629 & 330 & 161 & 298 & 452 & 325 & 100 & 522 & 385 & 473 & 2 & 6 & 6 & 385 & 6 & 8184 \\
\hline 22 & 24 & 2015 & 207 & 215 & 487 & 187 & 496 & 263 & 99 & 212 & 304 & 161 & 52 & 442 & 326 & 441 & 388 & 6 & 6 & 294 & 6 & 6514 \\
\hline 23 & 21 & 2016 & 108 & 179 & 168 & 141 & 237 & 120 & 189 & 349 & 341 & 225 & 49 & 202 & ( & 136 & 412 & 6 & 6 & 396 & 6 & 6 \\
\hline 24 & 2 & 9 & 348 & 269 & 655 & 160 & 937 & 300 & 125 & 539 & 344 & 412 & & 88 & 411 & 368 & 3 & 6 & 19 & 592 & 6 & 6 \\
\hline 25 & 2 & 2016 & 312 & 275 & 622 & 174 & 735 & 338 & 121 & 299 & 452 & 330 & 104 & 280 & 361 & 430 & 529 & 8 & 213 & 475 & 6 & 6 \\
\hline $\mathrm{n}$ & & & 27 & 28 & 28 & 23 & 27 & 29 & 29 & 29 & 26 & 26 & 27 & 28 & 24 & 29 & 9 & 11 & 23 & 28 & & -1 \\
\hline Mean & & & 293 & 295 & 563 & 176 & 697 & 358 & 150 & 318 & 417 & 274 & 95 & 310 & 391 & 440 & 491 & 76 & 266 & 398 & 6804 & 9380 \\
\hline STDEV & & & 110.6 & 133.4 & 212.5 & 65.1 & 249.0 & 158.1 & 56.1 & 128.5 & 124.9 & 105.6 & 44.1 & 128.8 & 149.7 & 161.0 & 164.2 & 16.1 & 114.2 & 144.0 & 3179.8 & 2897.0 \\
\hline
\end{tabular}

1) As given in the publication. In some cases, taurine is included in 'Total AA'.

2) Starch:Dextrose $=85: 0$

3) Starch:Dextrose $=56: 28$

4) Starch:Dextrose $=28: 57$

5) PFC method

6) No data published

7) Data was considered to be an outlier

8) In this study the total AA flow was much higher than in other study's, which may be the reason why the flow of a substantial number of amino acids was considered as outlier.

9) PRO data (1070 mg/kg DMI) was considered as outlier

\section{References referred to in Appendix 1.1}

1 Adedokun, S.A., C.M. Parsons, M.S. Lilburn, O. Adeola \& T.J. Applegate; 2007a. Endogenous amino acid flow in broiler chicks is affected by the age of birds and method of estimation. Poultry Science 86:2590-2597

2 Adedokun, S.A., C.M. Parsons, M.S. Lilburn, O. Adeola \& T.J. Applegate; 2007c. Comparison of ileal endogenous amino acid flows in broiler chicks and turkey poults. Poultry Science 86:1682-1689

3 Adedokun, S.A., P. Utterback, C.M. Parsons, O.Adeola, M.S. Lilburn and T.J. Applegate (2009). Comparison of endogenous amino acid flow in broilers, laying hens and caecestomised roosters. British Poultry Sci. 50: 359-365.

4 Adedokun, S.A., P. Jaynes, M.E. Abd El-Hack, R.L. Payne and T.J. Applegate, 2014. Standardized amino acid digestibility of meat and bone meal and soybean meal in laying hens and broilers. Poultry Scie. 93: 420-428.

5 Adeniyi, A.O. and O.A. Olukosi, 2015. Apparent and standardised ileal amino acid digestibility of wheat distillers dried grains with solubles with or without exogenous protease in broilers and turkeys. Br. Poultry Sci. 56: 239-246.

6 Golian, A., W. Guenter, D. Hoehler, H. Jahanian \& C.M. Nyachoti; 2008. Comparison of various methods for endogenous ileal amino acid flow determination in broiler chickens. Poultry Science 87:706-712

7 Kadim, I.T., P.J. Moughan \& V. Ravindran; 2002. Ileal amino acid digestibility assay for the growing meat chicken - comparison of ileal and excreta amino acid digestibility in the chicken. British Poultry Science 44:588-597

8 Kim, E.J., P.L. Utterback and C.M. Parons, 2011. Development of a precision-fed ileal amino acid digestibility assay using 3-week-old 
broiler chicks. Poultry Science 90: 396-401

9 Kong, C. and O. Adeola, 2013. Ileal endogenous amino acid flow response to nitrogen-free diets with differing ratios of corn starch to dextrose in broiler chickens/ Poultry Sci. 92: 1276-1282

10 Kong, C. and O. Adeola; 2013a. Additivity of amino acid digestibility in corn and soybean meal for broiler chickens and White Pekin ducks. Poultry Sci. 92, 2381-2388

11 Kong, C. and O. Adeola; 2013b. Comparative amino acid digestibility for broiler chickens and White Pekin ducks. Poultry Sci. 92,2367-2374

12 Ravindran, V., L.I. Hew, G. Ravindran \& W.L. Bryden; 2004. Endogenous amino acid flow in the avian ileum: quantification using three techniques. British Journal of Nutrition 92:217-223

13 Ravindran, V., P.C.H. Morel, S.M. Rutherford \& D.V. Thomas; 2009. Endogenous flow of amino acids in the avian ileum as influenced by increasing dietary peptide concentrations. British Journal of Nutrition 101:822-828

14 Ravindran, V., M.R. Abdollahi and S.M. Bootwalla. 2014. Nutrient analysis, metabolizable energy and digestible amino acids of soybean meals of different origins for broilers. Poultry Sci. 93: 2567-2577

15 Ravindran, V., O. Adeola, M. Rodehutscord, H.Kluth, J.D. van der Klis, E. van Eerden, A. van Helmbrecht, 2017. An. Feed Sci. Techn. 225: 62-72.

16 Scheele, C.W., C. Kwakernaak and J.D. van der Klis, 1992. De ileale eiwit- en aminozuurverteerbaarheid van 24 grondstoffen bij slachtkuikens. Spelderholt Uitgave No. 588

17 Siriwan, P., W.L. Bryden, Y. Mollah \& E.F. Annison; 1993. Measurement of endogenous amino acid losses in poultry. Br. Poultry Sci. 34:939-949

18 Siriwan, P., W.L. Bryden, \& E.F. Annison; 1994. Use of guanidinated protein to measure losses of endogenous amino acid in poultry. Br. J. Nutr. 71:515-529

19 Soleimani, A.F., A. Kasim, A.R. Alimon, A. Meinmandipour and I. Zulkifli, 2010. Ileal endogenous amino acid flow of broiler chickens under high ambient temperature. J. Anim. Physiology and Anim. Nutrition 94: 641-647.

20 Szczurek, W., 2009. Standardized ileal digestibility of amino acids from several grains ans protein-rich feedstuffs in broiler chickens at the age of 30 days. J. Anim. And Feed Sci. 18: 662-676.

21 Szczurek, W., 2010. Standardized ileal digestibility of amino acids in some cereals, rapeseed products and maize DDGS for broiler chickens at the age of 14 days. J. Anim. And Feed Sci. 19: 73-81.

22 Toghyani, M., N. Rodgers, P.A. lji and R.A. Swick, 2015. Standardized ileal amino acid digestibility of expeller-extracted canola meal subjected to different processing conditions for starter and grower broiler chickens. Poultry Sci. 94: 992-1002.

23 Ullah, Z., G. Ahmed, M.u. Nisa and M. Sarwar, 2016. Standardized ileal amino acid digestibility of commonly used feed ingredients in growing broilers. Asia Australas. J. Anim. Sci 29: 1322-1330

24 Valencia, D.G., M.P. Serrano, E. Jiménez-Moreno, R. Lázaro and G.G. Mateos, 2009. Ileal digestibility of amino acids of pea protein concentrate and soya bean sources in broiler chicks. Livestock Sci. 121: 21-27.

25 Woyengo, T.A., R. Patterson, B.A. Slominski, E. Beltranena and R.T. Zijlstra, 2016. Nutritive value of cold-pressed camelina cake with or without supplementation of multi-enzyme in broiler chickens. Poultry Sci. 95, 2314-2321. 


\subsection{Results for REG (Regression) method}

\begin{tabular}{|c|c|c|c|c|c|c|c|c|c|c|c|c|c|c|c|c|c|c|c|c|c|c|}
\hline Ref* $^{*}$ & Age (d) & $\begin{array}{r}\text { Year of } \\
\text { publication }\end{array}$ & ALA & ARG & ASP & CYS & GLU & GLY & HIS & ILE & LEU & LYS & MET & PHE & PRO & SER & THR & TRP & TYR & VAL & $\begin{array}{l}\text { Total } \\
\text { AA 1) }\end{array}$ & CP \\
\hline 1 & $15^{1)}$ & 2007 & 180 & 185 & 362 & 131 & 285 & 219 & 74 & 137 & 265 & 176 & 60 & 178 & 241 & 210 & 303 & 5) & 136 & 197 & 3851 & 5) \\
\hline 1 & $21^{1)}$ & 2007 & 125 & 132 & 197 & 139 & 67 & 176 & 48 & 93 & 162 & 65 & 19 & 117 & 127 & 145 & 154 & 5) & 83 & 139 & 2329 & 5) \\
\hline 2 & 21 1) 2) & 2007 & 163 & 161 & 315 & 147 & 386 & 199 & 68 & 155 & 234 & 167 & 40 & 151 & 231 & 260 & 147 & 5) & 123 & 198 & 4,074 & 5) \\
\hline 3 & $21^{3)}$ & 2008 & 209 & 181 & 406 & 138 & 588 & 234 & 97 & 237 & 301 & 187 & 73 & 396 & 263 & 396 & 410 & 88 & 5) & 283 & 5331 & 5) \\
\hline 3 & $21^{11}$ & 2008 & 262 & 206 & 484 & 148 & 695 & 270 & 64 & 321 & 341 & 191 & 73 & 441 & 311 & 577 & 493 & 72 & 5) & 341 & 4645 & 5) \\
\hline 4 & \begin{tabular}{|c|}
$35-45^{1)}$ \\
\end{tabular} & 1994 & 270 & 180 & 810 & 5) & 1780 & 310 & 130 & 520 & 480 & 190 & 80 & 210 & 5) & 970 & 610 & 5) & 150 & 500 & 7190 & 5) \\
\hline$n$ & & & 6 & 6 & 6 & 5 & 6 & 6 & 6 & 6 & 6 & 6 & 6 & 6 & 5 & 6 & 6 & 2 & 4 & 6 & 6 & \\
\hline Mean & & & 202 & 174 & 429 & 141 & 634 & 235 & 80 & 244 & 297 & 163 & 58 & 249 & 235 & 426 & 353 & 80 & 123 & 276 & 4570 & \\
\hline \begin{tabular}{|l|} 
STDEV \\
\end{tabular} & & & 56.9 & 25.2 & 209.8 & 7.0 & 604.0 & 48.8 & 29.2 & 157.7 & 108.3 & 48.7 & 23.6 & 135.7 & 67.6 & 307.5 & 186.2 & 11.3 & 28.9 & 130.8 & 1626.9 & \\
\hline
\end{tabular}

*): The following study was not included in the database: Adedokun, S.A., K.M. Ajuwon, L.F. Romero and O. Adeola, 2012. Ileal endogenous losses: Response of broiler chickens to fiber and mild coccidial vaccine challenge. Poultry Sci. 91: 899-907. The endogenous amino acid flow in this study was approx. 1.5 times higher than obtained by Adedokun et al. in two other studies which have been incorporated in the database. The authors themselves also mention the much higher endogenous amino acid flow and suggest a number of reasons. The observation that the animals lost approx. $68 \mathrm{~g}$ BW during the 5 -d experimental period is not mentioned, but is the reason why we exclude this study.

1): Using casein as a protein source.

2): The regression analysis was done by ourselves, using the mean data published.

3): Using $\mathrm{EHC}$ as a protein source.

4): $\quad$ PFC method used

5): $\quad$ No data published

\section{References referred to in Appendix 1.2}

1 Adedokun, S.A., C.M. Parsons, M.S. Lilburn, O. Adeola \& T.J. Applegate; 2007a. Endogenous amino acid flow in broiler chicks is affected by the age of birds and method of estimation. Poultry Science 86:2590-2597

2 Adedokun, S.A., C.M. Parsons, M.S. Lilburn, O. Adeola \& T.J. Applegate; 2007c. Comparison of ileal endogenous amino acid flows in broiler chicks and turkey poults. Poultry Science 86:1682-1689

3 Golian, A., W. Guenter, D. Hoehler, H. Jahanian \& C.M. Nyachoti; 2008. Comparison of various methods for endogenous ileal amino acid flow determination in broiler chickens. Poultry Science 87:706-712

4 Siriwan, P., W.L. Bryden, \& E.F. Annison; 1994. Use of guanidinated protein to measure losses of endogenous amino acid in poultry. Br. J. Nutr. 71:515-529 
1.3 Results for HDP (Highly digestible protein) method

\begin{tabular}{|c|c|c|c|c|c|c|c|c|c|c|c|c|c|c|c|c|c|c|c|c|c|c|}
\hline Ref & Age (d) & $\begin{array}{l}\text { Year of } \\
\text { publication }\end{array}$ & ALA & ARG & ASP & CYS & GLU & GLY & HIS & ILE & LEU & LYS & MET & PHE & PRO & SER & THR & TRP & TYR & VAL & $\begin{array}{l}\text { Total } \\
\text { AA 1) }\end{array}$ & $\mathrm{CP}$ \\
\hline 1 & 15 & 2007 & 271 & 222 & 568 & 154 & 1015 & 275 & 117 & 343 & 363 & 315 & 99 & 207 & 372 & 518 & 417 & 1) & 173 & 370 & 6387 & 1) \\
\hline 1 & 21 & 2007 & 285 & 236 & 551 & 184 & 1075 & 297 & 124 & 368 & 378 & 305 & 100 & 209 & 383 & 559 & 387 & 1) & 173 & 392 & 6550 & 1) \\
\hline 2 & 15 & 2009 & 311 & 262 & 660 & 180 & 1,152 & 317 & 138 & 388 & 422 & 379 & 113 & 242 & 436 & 592 & 474 & 1) & 205 & 423 & 7,367 & 1) \\
\hline 2 & 21 & 2009 & 263 & 222 & 535 & 192 & 1,044 & 279 & 117 & 354 & 358 & 307 & 91 & 203 & 381 & 546 & 365 & 1) & 172 & 373 & 7,216 & 1) \\
\hline 13 & 21 & 2010 & 287 & 200 & 538 & 34 & 1273 & 248 & 284 & 381 & 370 & 160 & 98 & 151 & 394 & 683 & 548 & 1) & 138 & 347 & 1) & 7,713 \\
\hline$n$ & & & 5 & 5 & 5 & 5 & 5 & 5 & 5 & 5 & 5 & 5 & 5 & 5 & 5 & 5 & 5 & 0 & 5 & 5 & 4 & 1 \\
\hline Mean & & & 283 & 228 & 570 & 149 & 1112 & 283 & 156 & 367 & 378 & 293 & 100 & 202 & 393 & 580 & 438 & & 172 & 381 & 6880 & 7713 \\
\hline STDEV & & & 18.4 & 22.8 & 51.8 & 65.7 & 103.6 & 25.8 & 72.1 & 18.6 & 25.6 & 80.5 & 8.0 & 32.7 & 25.2 & 63.6 & 73.8 & & 23.7 & 28.4 & 483.7 & \\
\hline
\end{tabular}

References referred to in Appendix 1.3

1 Adedokun, S.A., C.M. Parsons, M.S. Lilburn, O. Adeola \& T.J. Applegate; 2007a. Endogenous amino acid flow in broiler chicks is affected by the age of birds and method of estimation. Poultry Science 86:2590-2597

2 Adedokun, S.A., C.M. Parsons, M.S. Lilburn, O. Adeola \& T.J. Applegate; 2007c. Comparison of ileal endogenous amino acid flows in broiler chicks and turkey poults. Poultry Science 86:1682-1689

13 Woyengo, T.A., E. Kiarie and C.M. Nyachoti; 2010. Metabolizable energy and standardized ileal digestible amino acid contents of expeller-extracted canola meal fed to broiler chicks. Poultry Science 89: 1182-1189 


\subsection{Results for EHC (Enzymatic Hydrolysed Casein) method}

\begin{tabular}{|c|c|c|c|c|c|c|c|c|c|c|c|c|c|c|c|c|c|c|c|c|c|c|}
\hline Ref & Age (d) & $\begin{array}{l}\text { Year of } \\
\text { publication }\end{array}$ & ALA & ARG & ASP & CYS & GLU & GLY & HIS & ILE & LEU & LYS & MET & PHE & PRO & SER & THR & TRP & TYR & VAL & $\begin{array}{l}\text { Total } \\
\text { AA 1) }\end{array}$ & $\mathbf{C P}$ \\
\hline 1 & $21^{1)}$ & 2008 & 338 & 248 & 979 & 164 & 1932 & 331 & 194 & 388 & 427 & 274 & 111 & 607 & 781 & 805 & 648 & 80 & & 423 & & 8730 \\
\hline 2 & $37^{11)}$ & 2009 & 351 & 245 & 674 & 235 & 903 & 698 & 123 & 246 & 350 & 251 & 109 & 231 & 561 & 522 & 583 & & 192 & 346 & 6619 & 8194 \\
\hline$n$ & & & 2 & 2 & 2 & 2 & 2 & 2 & 2 & 2 & 2 & 2 & 2 & 2 & 2 & 2 & 2 & 1 & 1 & 2 & 1 & 2 \\
\hline Mean & & & 345 & 247 & 827 & 200 & 1418 & 515 & 159 & 317 & 389 & 263 & 110 & 419 & 671 & 664 & 616 & 80 & 192 & 385 & 6619 & 8462 \\
\hline STDEV & & & 9.2 & 2.1 & 215.7 & 50.2 & 727.6 & 259.5 & 50.2 & 100.4 & 54.4 & 16.3 & 1.4 & 265.9 & 155.6 & 200.1 & 46.0 & & & 54.4 & & 379.0 \\
\hline
\end{tabular}

1): Using casein as a protein source.

\section{References referred to in Appendix 1.4}

1 Golian, A., W. Guenter, D. Hoehler, H. Jahanian \& C.M. Nyachoti; 2008. Comparison of various methods for endogenous ileal amino acid flow determination in broiler chickens. Poultry Science 87:706-712

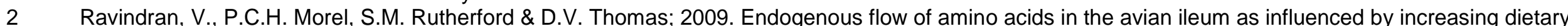
peptide concentrations. British Journal of Nutrition 101:822-828 


\section{Appendix 2. Literature data on the amino acid composition of ileal endogenous protein in poultry.}

Essential amino acids: ARG, HIS, ILE, LEU, LYS, MET, PHE, THR, TRP, VAL. Non-essential amino acids: ALA, ASP, CYS, GLU, GLY, PRO, SER, TYR. (Ravindran.\& Bryden, 1999)

\begin{tabular}{|c|c|c|c|c|c|c|c|c|c|c|c|c|c|c|c|c|c|}
\hline Reference & 1 & $2^{\text {a) }}$ & $2^{\mathrm{b})}$ & $2^{\mathrm{c})}$ & $2^{\text {d) }}$ & 3 & 4 & 5 & 6 & 7 & 7 & $8^{e)}$ & 9 & 10 & 11 & $\min$ & $\max$ \\
\hline Age (days) & 21 & 26 & 26 & 26 & 26 & 19 & 26 & 21 & 35 & 35 & 35 & 42 & 24 & 21 & 21 & & \\
\hline Exp. Method & NFD & NFD & NFD & NFD & NFD & NFD & NFD & NFD & NFD & NFD & EHC50 & NFD & NFD & NFD & NFD & & \\
\hline N-flow (g/kg DMI) & 10,493 & 12,969 & 13,825 & 12,844 & 19,806 & 11,744 & 12,244 & 4,368 & 7,329 & 7,700 & 8,194 & 9,597 & 8,184 & & 7,713 & & \\
\hline Amino acid & \multicolumn{17}{|c|}{$\mathrm{g} / \mathrm{kg} \mathrm{CP}$ b) c) } \\
\hline ALA & 37.0 & 44.1 & 41.4 & 42.8 & 45.7 & 31.8 & 30.8 & 49.7 & 40.0 & 37.7 & 42.9 & 36.4 & 31.8 & 34.8 & 37.2 & 30.8 & 49.7 \\
\hline ARG & 37.1 & 44.3 & 43.3 & 45.6 & 51.4 & 29.9 & 30.1 & 46.5 & 38.1 & 30.9 & 30.0 & 48.9 & 33.0 & 26.9 & 25.9 & 25.9 & 51.4 \\
\hline ASP & 68.8 & 78.3 & 76.9 & 79.6 & 82.7 & 63.1 & 61.4 & 98.4 & 82.8 & 71.7 & 82.3 & 59.8 & 74.8 & 65.5 & 69.8 & 59.8 & 98.4 \\
\hline CYS & 22.9 & 83.7 & 68.3 & 67.8 & 27.7 & 19.4 & 17.8 & 32.7 & 30.8 & 26.4 & 28.6 & 10.7 & 28.7 & 16.0 & 4.4 & 4.4 & 83.7 \\
\hline GLU & 88.2 & 103.1 & 98.5 & 102.3 & 107.6 & 71.9 & 74.7 & 112.6 & 98.3 & 90.0 & 110.2 & 88.7 & 76.1 & 93.7 & 165.1 & 71.9 & 165.1 \\
\hline GLY & 43.3 & 50.4 & 48.2 & 48.8 & 47.9 & 32.7 & 35.2 & 56.1 & 69.4 & 61.4 & 85.2 & 41.7 & 40.4 & 30.0 & 32.2 & 30.0 & 85.2 \\
\hline HIS & 14.7 & 19.1 & 18.5 & 19.3 & 21.0 & 12.4 & 13.1 & 20.8 & 21.6 & 17.3 & 15.1 & 21.2 & 15.2 & 12.5 & 36.8 & 12.4 & 36.8 \\
\hline ILE & 32.7 & 41.7 & 40.2 & 41.5 & 43.2 & 30.3 & 30.6 & 45.8 & 39.2 & 32.4 & 30.0 & 34.1 & 32.5 & 53.9 & 49.4 & 30.0 & 53.9 \\
\hline LEU & 54.0 & 67.5 & 64.6 & 68.2 & 73.2 & 45.9 & 46.1 & 68.2 & 59.9 & 46.9 & 42.7 & 55.7 & 46.7 & 34.4 & 48.0 & 34.4 & 73.2 \\
\hline LYS & 32.9 & 48.6 & 48.0 & 50.3 & 62.4 & 31.8 & 31.2 & 39.6 & 28.5 & 29.1 & 30.7 & 38.9 & 24.7 & 41.2 & 20.7 & 20.7 & 62.4 \\
\hline MET & 10.2 & 13.3 & 12.4 & 13.8 & 18.2 & 7.3 & 8.2 & 14.9 & 13.8 & 11.6 & 13.4 & 8.4 & 8.0 & 21.7 & 12.7 & 7.3 & 21.7 \\
\hline $\mathrm{PHE}$ & 57.9 & 38.6 & 37.8 & 39.8 & 41.7 & 27.5 & 28.2 & 96.2 & 39.2 & 25.5 & 28.2 & \begin{tabular}{|l|}
41.4 \\
\end{tabular} & 63.8 & 35.8 & 19.6 & 19.6 & 96.2 \\
\hline PRO & 46.5 & 52.0 & 47.4 & 48.9 & 47.9 & 35.3 & 42.4 & 66.2 & & 139.6 & 68.6 & 35.5 & 50.0 & 41.1 & 51.1 & 35.3 & 139.6 \\
\hline SER & 53.0 & 54.8 & 51.2 & 52.9 & 51.8 & 45.0 & 41.2 & 78.5 & 57.8 & 53.8 & 63.7 & 57.0 & 67.7 & 36.8 & 88.6 & 36.8 & 88.6 \\
\hline THR & 53.1 & 62.0 & 55.8 & 56.7 & 41.7 & 49.1 & 47.5 & 99.4 & 69.8 & 68.8 & 71.1 & 56.1 & 59.6 & 56.3 & 71.1 & 41.7 & 99.4 \\
\hline TRP & & 5.2 & 5.4 & 5.5 & 8.4 & 4.4 & 7.1 & 16.3 & 13.0 & & & 5.2 & & & & 4.4 & 16.3 \\
\hline TYR & & 30.1 & 29.1 & 30.8 & 32.2 & 23.8 & 23.4 & & 34.5 & 26.5 & 23.4 & 27.6 & & 19.2 & & 19.2 & 34.5 \\
\hline VAL & 43.5 & 50.9 & 48.8 & 50.5 & 51.1 & 43.3 & 43.4 & 61.8 & 57.0 & 36.9 & 42.2 & 41.5 & 45.1 & 59.2 & 45.0 & 36.9 & 61.8 \\
\hline
\end{tabular}

a): Starch:Sugars=849:0; b): Starch:Sugars=849:0; c): Starch:Sugars=849:0; d): Starch:Sugars=849:0; e): Only data of control treatment are used.

b): Figures in dashed cells deviate $>2 *$ STDEV from the mean value for the respective amino acid.

c): Empty cells mean that no value has been reported.

References referred to in Appendix 2:

1 Adedokun, S.A., P. Jaynes, M.E. Abd El-Hack, R.L. Payne and T.J. Applegate, 2014. Standardized amino acid digestibility of meat and bone meal and soybean meal in laying hens and broilers. Poultry Scie. 93: 420-428. 
2 Kong, C. and O. Adeola, 2013. Ileal endogenous amino acid flow response to nitrogen-free diets with differing ratios of corn starch to dextrose in broiler chickens/ Poultry Sci. 92: 1276-1282

3 Kong, C. and O. Adeola; 2013a. Additivity of amino acid digestibility in corn and soybean meal for broiler chickens and White Pekin ducks. Poultry Sci. 92, 2381-2388

4 Kong, C. and O. Adeola; 2013b. Comparative amino acid digestibility for broiler chickens and White Pekin ducks. Poultry Sci. 92,2367-2374

5 Nandha N.K., 2011. Thesis, University of Manitoba, Winnipeg, Manitoba, Canada. Standardized ileal digestibility and requirement estimates of amino acids in three-week old broliers

6 Ravindran, V., L.I. Hew, G. Ravindran \& W.L. Bryden; 2004. Endogenous amino acid flow in the avian ileum: quantification using three techniques. British Journal of Nutrition 92:217-223

7 Ravindran, V., P.C.H. Morel, S.M. Rutherford \& D.V. Thomas; 2009. Endogenous flow of amino acids in the avian ileum as influenced by increasing dietary peptide concentrations. British Journal of Nutrition 101:822-828

8 Soleimani, A.F., A. Kasim, A.R. Alimon, A. Meinmandipour and I. Zulkifli, 2010. lleal endogenous amino acid flow of broiler chickens under high ambient temperature. J. Anim. Physiology and Anim. Nutrition 94: 641-647.

9 Toghyani, M., N. Rodgers, P.A. Iji and R.A. Swick, 2015. Standardized ileal amino acid digestibility of expeller-extracted canola meal subjected to different processing conditions for starter and grower broiler chickens. Poultry Sci. 94: 992-1002.

10 Valencia, D.G., M.P. Serrano, E. Jiménez-Moreno, R. Lázaro and G.G. Mateos, 2009. Ileal digestibility of amino acids of pea protein concentrate and soya bean sources in broiler chicks. Livestock Sci. 121: 21-27.

11 Woyengo, T.A., E. Kiarie and C.M. Nyachoti, 2010. Metabolizable energy and standardized ileal digestible amino acid contents of expellerextracted canola meal fed to broiler chickens. Poultry Sci. 89, 1182-1189. 


\section{Appendix 3. Proposed basal endogenous ileal AA flow (g per kg DMI).}

In the first column, the proposed values from this study are stated. The basal endogenous ileal AA flow, as proposed by Lemme et al. (2004), based on studies with the EHC method, is also given. For comparison, the findings of Lemme et al. (2004) from studies using the REG and the NFD method are given in the last two columns.

\begin{tabular}{|c|c|c|c|c|}
\hline & \multicolumn{4}{|c|}{ Basal endogenous ileal AA flow, g per kg DMI } \\
\hline & \multirow{2}{*}{$\begin{array}{c}\text { This study }{ }^{1)} \\
\text { Mean }\end{array}$} & \multicolumn{3}{|c|}{ Lemme et al., 2004 (Mean \pm SD) } \\
\hline & & EHC method 2) & REG method & NFD method \\
\hline ALA & 0.278 & - & - & - \\
\hline ASP & 0.568 & - & - & - \\
\hline CYS & 0.166 & $0.17 \pm 0.03$ & $0.41(n=1)$ & $0.21 \pm 0.01$ \\
\hline HIS & 0.138 & $0.21 \pm 0.09$ & $0.35 \pm 0.03$ & $0.19 \pm 0.17$ \\
\hline ILE & 0.312 & $0.39 \pm 0.14$ & $0.65 \pm 0.40$ & $0.34 \pm 0.09$ \\
\hline LEU & 0.379 & $0.38 \pm 0.09$ & $1.28 \pm 0.28$ & $0.48 \pm 0.05$ \\
\hline LYS & 0.252 & 0.26 & - & - \\
\hline MET & 0.090 & $0.08 \pm 0.01$ & $0.31(n=1)$ & $0.14 \pm 0.04$ \\
\hline TRP & 0.078 & $0.08 \pm 0.01$ & - & $0.11(n=1)$ \\
\hline TYR & 0.209 & - & - & - \\
\hline VAL & 0.367 & $0.45 \pm 0.12$ & $0.82 \pm 0.06$ & $0.42 \pm 0.05$ \\
\hline $\mathrm{CP}$ & - & $9,23 \pm 1.26$ & $16.34(n=1)$ & $6.28 \pm 1.37$ \\
\hline Total AA ${ }^{3)}$ & 5.920 & & & \\
\hline
\end{tabular}

1) Mainly based on NFD data, but also on REG,HDP and few EHC data (see Table 3).

2) According to Lemme et al. (2004), EHC is the preferred method

3) Calculated as the sum of mean values for the individual amino acids 